\title{
Leptomeningeal cells induce synaptic failure via Cathepsin B-mediated IL-1 $\beta$ production after Porphyromonas gingivalis infection
}

\section{Wanyi Huang}

Kyushu University Faculty of Dental Science Graduate School of Dental Science: Kyushu Daigaku Shigaku Kenkyuin Shigakuka

\section{Fan Zeng}

Kyushu University Faculty of Dental Science Graduate School of Dental Science: Kyushu Daigaku Shigaku Kenkyuin Shigakuka

\section{Yebo Gu}

Kyushu University Faculty of Dental Science Graduate School of Dental Science: Kyushu Daigaku Shigaku Kenkyuin Shigakuka

\section{Muzhou Jiang}

Kyushu University Faculty of Dental Science Graduate School of Dental Science: Kyushu Daigaku Shigaku Kenkyuin Shigakuka

\section{Xinwen Zhang}

China Medical University

\section{Xu Yan}

China Medical University

\section{Tomoko Kadowaki}

Nagasaki University: Nagasaki Daigaku

\section{Shinsuke Mizutani}

Kyushu University Faculty of Dental Science Graduate School of Dental Science: Kyushu Daigaku Shigaku Kenkyuin Shigakuka

\section{Haruhiko Kashiwazaki}

Kyushu University Faculty of Dental Science Graduate School of Dental Science: Kyushu Daigaku Shigaku Kenkyuin Shigakuka

\section{Junjun Ni}

Beijing Institute of Technology

\section{Zhou Wu ( $D$ zhouw@dent.kyushu-u.ac.jp)}

Kyushu University https://orcid.org/0000-0002-4910-9037

\section{Research}


Keywords: Porphyromonas gingivalis, Leptomeningeal cells, Alzheimer's disease, Cathepsin B, IL-1 $\beta$, BDNF

Posted Date: November 20th, 2020

DOI: https://doi.org/10.21203/rs.3.rs-111412/v1

License: (1) This work is licensed under a Creative Commons Attribution 4.0 International License. Read Full License 


\section{Abstract}

Background: Synaptic failure is the earliest sign before Alzheimer's disease (AD) onset and closely associated with cognitive decline. Clinical studies have shown that periodontitis is positively correlated with both the onset and progression of $A D$, and preclinical studies have shown that Porphyromonas gingivalis ( $P$. gingivalis) and its virulence factors induced memory decline in mice. However, the mechanisms underlying the involvement of $P$. gingivalis in memory decline remain unclear.

Methods: Fifteen-month-old female C57/BL6J mice were intraperitoneally injected with $P$. gingivalislearning and memory were evaluated by step through passive avoidance tests. Immunofluorescent staining was used to examine the expression of IL-1 $\beta$ and synaptic markers. Primary leptomeningeal cells and primary cortical neurons were used to evaluate the its effects on synaptic generation and plasticity. The expression of related molecules was examined by Q-PCR and Western blotting. Pharmacological and genetic approaches were used to explore the roles of leptomeningeal cells in synaptic changes after $P$. gingivalis infection.

Results: P. gingivalis infection induced the increased expression of IL-1 $\beta$ in leptomeninges and decreased expression of synaptophysin (SYP) in the cortex proximity of the leptomeninges, which was accompanied by memory decline in middle-aged mice. NLRP3 inflammasome activation was involved in augmenting the IL-1 $\beta$ secretion by primary leptomeningeal cells after $P$. gingivalis infection. Cathepsin $B$ (CatB) mediated the activation of both NLRP3 inflammasome and NF-KB in $P$. gingivalis-infected primary leptomeningeal cells. In contrast, $P$. gingivalis-infected leptomeningeal cells induced an IL-1 $\beta$-dependent decrease in pre- and post-synaptic molecules in primary cortical neurons, as determined by the pharmacological blockage of the IL-1 receptor. P. gingivalis-infected leptomeningeal cells also induced the IL-1 $\beta$-dependent suppression of BDNF signaling in cultured N2a neurons. Furthermore, propolis produced by honeybees, suppressed the expression of IL-1 $\beta$ but increased that of BDNF in P. gingivalisinfected leptomeningeal cells.

Conclusion: The CatB-mediated IL-1 $\beta$ production was augmented in leptomeningeal cells, resulting in synaptic failure and blockage of BDNF signaling in neurons during $P$. gingivalis infection. These findings highlight a new mechanism underlying the involvement of periodontitis in AD initiation and suggest that CatB may be an early intervention therapeutic target for delaying the onset of $A D$ during $P$. gingivalis infection.

\section{Background}

The rate of Alzheimer's disease (AD), the most prevalent type of dementia, is increasing as the global elderly population grows. As no effective treatment of AD has yet been established, it is extremely important to identify early risk factors for delaying the onset and pathological progression of AD.

Cognitive decline is one of the main symptoms of $A D$ onset, and synaptic failure is considered the earliest sign before the onset of $A D$, being closely associated with the observation of cognitive decline in $A D$ 
patients [1, 2]. It was reported that the expression of synaptic molecules, such as pre-synaptic makers synaptophysin (SYP), vesicular glutamate transporter1(VGLUT1), synapsin1 (SYN1), and the postsynaptic marker postsynaptic density protein 95 (PSD95) was reduced in the brain of patients with mild cognitive impairment $(\mathrm{MCl})$, the pre-clinical stage $A D$, as well as $A D[3,4]$. In addition, evidence strongly suggests that deficits in brain-derived neurotrophic factor (BDNF) signaling, a major regulatory pathway for synaptic generation and plasticity $[5,6]$, contribute to the pathogenesis of neurodegenerative disorders, including AD [7].

Periodontitis, the most common chronic oral infection disorder in adults, has drawn attention as a risk factor for $A D$, since morbidity of periodontitis is positively correlated with both the onset and pathological progression of AD clinically [8, 9]. Porphyromonas gingivalis (P. gingivalis), a keystone pathogen for periodontitis [10], is recognized as the major linking factor between periodontitis and AD, since $P$. gingivalis DNA as well as its virulence factors, including lipopolysaccharide (LPS) and gingipain, have been detected in the cortex and cerebrospinal fluid (CSF) of AD patients $[11,12]$.

Recently, preclinical studies have suggested that periodontitis may contribute to AD onset, since exposure to $P$. gingivalis and its LPS as well as gingipain induced the hallmarks of AD-like pathologies, including amyloid $(A \beta)$ accumulation, neuroinflammation and memory decline, in mice [13-15]. Furthermore, we recently found that the memory decline induced by $P$. gingivalis occurred earlier than that induced by $P$. gingivalis LPS in middle-aged mice $[13,14]$; however, the involvement of $P$. gingivalis in the synaptic changes remains unclear.

As a master pro-inflammatory cytokine for inducting AD pathogenesis, IL-1 $\beta$ has been accepted to induce synapse failures $[16,17]$. It is well known that NOD-, LRR- and pyrin domain-containing protein 3(NLRP3) inflammasome activation mediates the IL- $1 \beta$ production in response to infectious microbes, including $P$. gingivalis $[18,19]$. In addtion, Cathepsin B (CatB), a cysteine lysosomal protease, has been shown to perform a mediating role in IL-1 $\beta$ production in response to different stimulations $[20,21]$.

The leptomeninges, the innermost layer of meninges, anatomically envelope the central nervous system (CNS), including the brain. As the interfaces between systemic circulation and brain, leptomeningeal cells have been found to produce pro-inflammatory mediators, including IL-1 $\beta$, which induce neuroinflammation in response to systemic inflammatory signals, such as $P$. gingivalis LPS [22-25]. In addition to forming a physical barrier (the blood-cerebrospinal fluid barrier [BCSFB]), leptomeningeal cells are known to constantly produce and secrete soluble factors [26, 27]that directly affect neurons [28].

A resinous substance produced by honeybees as a defense against intruders [29], propolis has been shown to induce effects of anti-oxidation, anti-inflammation [30] and neuroprotection [31, 32]. We previously found that propolis regulates the production of inflammatory mediators by immune cells in both the periphery and brain and protects against oxidative stress-induced damage in neurons [30, 32], which may help improve the cognitive function in elderly individuals [33]. 
Based on these anatomical structures of leptomeningeal cells along with our previous findings, we hypothesized that leptomeningeal cell-induced neuroinflammation might be involved in synaptic failure by releasing soluble factors during $P$. gingivalis infection. We therefore explored whether or not $P$. gingivalis infection was an early risk factor for $A D$ onset.

Using our conducted cellular models, we focused on mechanisms of IL-1 $\beta$ production by leptomeningeal cells after $P$. gingivalis infection and the effects of leptomeningeal cell-produced IL-1 $\beta$ on the expression of synaptic molecules, as well as BDNF-evolved signaling in neurons. The present work highlights a new mechanism underlying the involvement of periodontitis in the initiation of and strongly suggests the utility of CatB as a therapeutic target for early intervention delaying the onset and pathological progression of $\mathrm{AD}$ during $P$. gingivalis infection.

\section{Methods}

\section{Animals}

Fifteen-month-old female mice on a C57/BL6J background (Japan SLC, Incorporation, Japan) maintained in a specific-pathogen-free condition were used. All animal treatments were in accordance of the protocols approved by the Institutional Animal Care and Use Committee of Kyushu University. The mice ( $\mathrm{n}=6$ each group) were intraperitoneally injected with $P$. gingivalis $\left(1 \times 10^{8} \mathrm{CFU} /\right.$ mouse $)$ in $100 \mu \mathrm{L}$ phosphate-buffered saline (PBS) every 3 days for three consecutive weeks as the $P$. gingivalisinfected mice. The age-matched mice $(n=6)$ were intraperitoneally injected with $100 \mu \mathrm{L}$ PBS in the same time course as the controls.

\section{Step-through Passive Avoidance Test}

The step-through passive avoidance test was used to monitor the mice memory decline. The test device contains an illuminated compartment and a dark compartment with an electrifiable grid floor, which were separated by a guillotine door. During the acquisition period, each mouse was placed in the illuminated compartment for $30 \mathrm{~s}$ then the door was opened. When the mouse fully entranced the dark compartment, the door was closed and the mouse was given an electric shock (0.2 mA, $2 \mathrm{~s})$. At the endpoint of the acquisition period, the mice were able to stay in the illuminated compartment for $300 \mathrm{~s}$. The test was carried out since the first day of the $P$. gingivalis injection for every 7 days for 3 weeks. The latency was set up to $300 \mathrm{~s}$ and was recorded during the whole test period.

\section{Bacteria Culture}

Porphyromonas gingivalis ATCC 33277 were cultured on blood BHI (brain heart infusion) agar plate containing $40 \mathrm{mg} / \mathrm{ml}$ trypot-soya agar (Nissui Pharmaceutical, Tokyo, Japan), $5 \mathrm{mg} / \mathrm{ml} \mathrm{BHI} \mathrm{(Becton,}$ Dickinson and Company, Franklin Lakes, NJ, USA), $1 \mathrm{~g} / \mathrm{ml}$ cysteine( Wako Pure Chemical Industries, Osaka, Japan), $5 \mu \mathrm{g} / \mathrm{ml}$ hemin (Sigma-Aldrich, St. Louis, MO, USA), $1 \mu \mathrm{g} / \mathrm{ml}$ menadione (Sigma-Aldrich), $5 \%$ defibrinated sheep blood (Nippon Bio-test laboratories, Tokyo, Japan) in bactron anaerobic chamber (Shel Lab, Cornelius, OR, USA) with mix gas of $10 \% \mathrm{CO}_{2}, 10 \% \mathrm{H}_{2}, 80 \% \mathrm{~N}_{2}$. P. gingivalis were grown in $\mathrm{BHI}$ 
medium containing $37 \mathrm{mg} / \mathrm{ml}$ BHl, $2.5 \mathrm{mg} / \mathrm{ml}$ yeast extract (Becton, Dickinson and Company), $1 \mathrm{~g} / \mathrm{ml}$ cysteine, $5 \mu \mathrm{g} / \mathrm{ml}$ hemin and $1 \mu \mathrm{g} / \mathrm{ml}$ menadione. $P$. gingivalis were pelleted by centrifuge at $6000 \times \mathrm{g}$ and suspended by neurobasal before treatment in cell culture and suspended by $100 \mu \mathrm{L}$ PBS for vivo experiments.

\section{Cell Culture}

Leptomeningeal cells were prepared from newborn mice brain on the background of C57black/6N mouse. Leptomeningeal tissues were cut into small pieces and plated on poly-D-lysine (Thermo Fisher Scientific, Japan) coated culture dishes, incubated in Minimum Essential Medium Eagle (MEM, Nissui Pharmaceutical co., Ltd., Japan) containing 10\% fetal bovine serum (Invitrogen, San Diego, CA, USA), $10 \mu \mathrm{g} / \mathrm{ml}$ insulin, $1 \%$ penicillin-streptomycin (Invitrogen) and $2 \mathrm{mg} / \mathrm{ml}$ glucose (Invitrogen) under $37^{\circ} \mathrm{C}$ and $5 \% \mathrm{CO}_{2}$ in humid atmosphere. For conditional medium collection, MEM was replaced by neurobasal or Dulbecco's Modified Eagle Medium (DMEM, Nissui Pharmaceutical co., Ltd., Japan) before infection with $P$. gingivalis.

Primary cortex neurons were prepared from newborn mice brain on the background of C57black/6N mouse. Dissected brain tissues were enzymatic digestion with a Neural Tissue Dissociation kit (Miltenyi Biotec). The separated neurons were kept in attachment medium for 24 hours and then replaced with maintenance medium which is neurobasal (Thermo Fisher) containing 10\% fetal bovine serum (Invitrogen, San Diego, CA, USA) and 1\% penicillin-streptomycin (Invitrogen). The cells were seeded at density of $1.25 \times 10^{6}$ cells $/ \mathrm{ml}$ for biochemical assay, $2 \times 10^{5}$ cells $/ \mathrm{ml}$ for immunohistochemistry. Arabinosylcytosine (Ara-C, Sigma-Aldrich, St. Louis, MO, USA) was added under $5 \mu \mathrm{M}$ on 3rd day out of vitro. In the conditional medium incubation experiments, leptomeningeal cell medium was replaced by neurobasal before infection with $P$. gingivalis.

Mouse neuroblastoma N2a cells purchased from American Type Culture Collection (Manassas, VA, USA) were cultured in Dulbecco's Modified Eagle Medium (DMEM, Nissui Pharmaceutical co., Ltd., Japan) containing 10\% fetal bovine serum (Invitrogen, San Diego, CA, USA), $10 \mu \mathrm{g} / \mathrm{ml}$ insulin, 1\% penicillinstreptomycin (Invitrogen) and $2 \mathrm{mg} / \mathrm{ml}$ glucose (Invitrogen) under $37^{\circ} \mathrm{C}$ and $5 \% \mathrm{CO}_{2}$ in humid atmosphere. The cells were seeded at a density of $2 \times 10^{5}$ cells/ml for western blotting. Retinoic acid (RA, $25 \mu \mathrm{M}$ ) were used to differentiate the cells for morphological change experiment.

\section{Reagents}

Cathepsin B inhibitor CA-074Me was purchased from Peptide (Japan). NLRP3 siRNA was purchased from Thermo Fisher Scientific (Waltham, MA, USA). Cytochalasin D (Cyto D) was purchased from SigmaAldrich, (St. Louis, MO, USA). IL-1 $\beta$ receptor antagonist IL-1Ra was purchased from Cayman Chemical Company (Ann Arbor, MI, USA). Human BDNF was purchased from Sigma-Aldrich Inc. (St. Louis, MO, USA). Brazilian green propolis ethanol extract (propolis) was obtained from Yamada Apiculture Center, Inc. (Okayama, Japan). 


\section{Cell Viability Assay}

Leptomeningeal cells were seeded in 96-well plates for 24 hours (5000 cells/well) and were infected with 1,5 and $10 \mathrm{MOls}$ of $P$. gingivalis or treated with several concentrations of propolis. Primary neurons were seed in 96- well plates for 2 weeks(5000cells/well) and were incubated with LCM for 24 hours. Cell viability was measured by Cell-Counting Kit-8 (CCK-8, Dojindo, Kumamoto, Japan) according to the manufacturer protocol. At different time points, $10 \mu \mathrm{L}$ CCK-8 solution was added to each well and incubated for 1 hour. The absorbance at $450 \mathrm{~nm}$ was measured by microplate reader.

\section{NLRP3 Knockdown With Small Interfering RNAs}

Leptomeningeal cells were seeded in 6-well plates in MEM and were transiently transfected with NLRP3 siRNA (169997, Thermo Fisher Scientific, USA) according to the manufacturer protocol. P. gingivalis was applied into the leptomeningeal cells after treatment with NLRP3 siRNA for 36 hours. The cells and condition medium were collected at 3 hours for Western blot and neuron treatment.

\section{Immunofluorescent Imaging}

Mice were anesthetized and sacrificed by intracardiac perfusion with PBS. The brain was extracted following immersed in $4 \%$ PFA at $4^{\circ} \mathrm{C}$ overnight and cryoprotected in $30 \%$ sucrose in PBS for 2 days then embedded in the optimal cutting temperature (OCT) compound (Sakura Finetechnical). The serial coronal frozen sections ( $14 \mu \mathrm{m}$ thick) were

prepared for immunofluorescent staining as reported previously [13].The sections were washed with PBS for $10 \mathrm{~min}$ at room temperature and incubated with antibody dilution buffer (1\% BSA and $0.4 \%$ TritonX100 in PBS) at $4{ }^{\circ} \mathrm{C}$ overnight and then with the primary antibodies in antibody dilution buffer at $4{ }^{\circ} \mathrm{C}$ for 2 days as follows: mouse anti-Fibronectin (1:1000; novusbio, Japan), goat anti-IL-1 $\beta$ (1:1000; R\&D), rabbit anti-Synaptophysin(1:1000;abcam). After wash with PBS, the sections were incubated with secondary antibodies in antibody dilution buffer at room temperature for 2 hours as follows: donkey anti-mouse Cy3 (1:1000; Jackson ImmunoResearch), donkey anti-goat Alexa 488(1:1000; Jackson ImmunoResearch), donkey anti-rabbit Alexa 488(1:1000; Jackson ImmunoResearch). The sections were then incubated with Hoechst in antibody dilution buffer (1:200; Sigma-Aldrich) and mounted in Vectashield anti-fading medium (Vector Laboratories, CA, USA). Fluorescence images were taken using a CLSM (C2si; Nikon, Japan)

The leptomeningeal cells and neurons were seeded on PEl-coated glasses in 24-well plates. For phagocytosis staining, P. gingivalis was fluorescence-labeled by $10 \mu \mathrm{M}$ CFDA SE (Vybrant CFDA SE Cell Tracer Kit, Invitrogen) and infected leptomeningeal cells for 40 minutes. For primary neuron staining, 30\% cell medium was replaced by leptomeningeal cells medium with or without $P$. gingivalis treatment. For N2a cells CREB activity, BDNF was administrated $2 \mathrm{~h}$ and IL-1Ra was administrated $1 \mathrm{~h}$ following the LCM treatment. The cells were fixed with $4 \%$ paraformaldehyde. After wash the cells with PBS twice, they were incubated with rabbit anti-LAMP1 (1:1000; Abcam), MAP2 (1:1000; Millipore), Phospho-CREB 
(1:1000, Cell Signal) overnight at $4{ }^{\circ} \mathrm{C}$ and incubated with anti-rabbit Alexa Cy3 (1:2000; Jackson ImmunoResearch) at room temperature for 2 hours then incubated with Hoechst (1:200; Sigma-Aldrich). For AO staining, leptomeningeal cells were infected with $P$. gingivalis for 2 hours and CV-Cathepsin $\mathrm{B}$ Detection Kit (Enzo, Switzerland) was used following the manufacturer protocol. Images were collected by a fluorescence microscope (C2si; Nikon). Image J software (64-bit Java 1.8.0 112) was used to calculate the neurite length and fluorescent density.

\section{Real-time Quantitative Polymerase Chain Reaction (QRT-PCR)}

The mRNA was isolated from the leptomeningeal cells and neurons at various time points. The total RNA was extracted using the RNAiso Plus (Takara) according to the manufacturer's instructions. A total of $2 \mu \mathrm{g}$ extracted RNA was reverse transcribed to cDNA using the ReverTra Ace qPCR RT Master Mix (TOYOBO). After an initial denaturation step at $95^{\circ} \mathrm{C}$ for $1 \mathrm{~min}$, temperature cycling was initiated. Each cycle consisted of denaturation at $95^{\circ} \mathrm{C}$ for $10 \mathrm{~s}$, annealing at $60{ }^{\circ} \mathrm{C}$ for $30 \mathrm{~s}$, and elongation for $30 \mathrm{~s}$. In total, 40 cycles were performed. The cDNA was amplified in duplicate using a THUNDERBIRD SYBR qPCR Mix (TOYOBO) with a Corbett Rotor-Gene RG-3000A Real-Time PCR System (Sydney, Australia). The data were evaluated using the RG-3000A software program (version Rotor-Gene 6.1.93, Corbett). The sequences of primer pairs were as follows: NLRP3, 5'-ACAAGCCTTTGCTCCAGACCCTAT-3' and 5'TGCTCTTCACTGCTATCAAGCCCT-3'; Caspase-1, 5'-CTTGTTTCTCTCCACGGC

A-3' and 5'-TCCAGGAGGGAATATGTGG-3'; CatB, 5'-GCAGCCAACTCTTGGAA

CCTT-3' and 5'-GGATTCCAGCCACAATTTCTG-3'; IL-1ß, 5'-CAACCAACAAG

TGATATTCTCCATG-3' and 5'-GATCCACACTCTCCAGCTGCA-3'; Synapsin I, 5'GGTCTTCCAGTTACCCGACA-3' and 5'-CAGCACAACATACCCTGTGG-3'; PSD95, 5'TCTGTGCGAGAGGTAGCAGA-3' and 5'-AAGCACTCCGTGAACTCCT

G-3';'synaptophysin: 5'-AGGTGCTGCAGTGGGTCTTTGC-3' and 5'-CCCCTTTAA

CGCAGGAGGGTGC-3'; VGLUT1, 5'-CCCCAAATCCTTGCACTTT-3' and 5'-AAC

AAATGGCCACTGAGAAACC-3' TLR2, 5'-CCATCGAAAAGAGCCACA-3' and 5'-CAGCAAAACAAGGATGGC-3'; BDNF, 5'-AAAATGCTCACATCCA-3' and 5'-GAACAAATGCTGGTCTT-3'.

\section{Immunoblotting Analyses}

The immunoblotting analyses were conducted as described previously [14]. The specimens were electrophoresed with $12 \%$ SDS-polyacrylamide gels and transferred to nitrocellulose membranes by electrophoresis. Following the blocking, the membranes were incubated at $4{ }^{\circ} \mathrm{C}$ overnight under gentle agitation with each primary antibody: goat anti- IL-1 (1:1000, R\&D), mouse anti- Caspase-1 (1:1000; AdipoGen), goat anti-CatB (1:1000; Santa Cruz Biotechnology), mouse anti-IkBa (1:1000; Cell Signaling), rabbit anti-Synaptophysin (1:20000; Abcam), rabbit anti-Phospho-Akt (Thr308, 1:1000, Cell Signal), rabbit 
anti-Phospho-Akt (Ser473, 1:1000, Cell Signal), rabbit anti-total Akt (1:1000, Cell Signal), rabbit antiPhospho-CREB (1:1000, Cell Signal), rabbit anti-total CREB (1:1000, Cell Signal). After washing, the membranes were incubated with HRP-labeled anti-goat (1:2000; GE Healthcare), anti-mouse (1:2000; R\&D Systems), anti-rabbit (1:2000; GE Healthcare), and mouse anti-actin (1:5,000, Abcam) for 2 hours at room temperature. After that, the HRP-labeled protein bands were detected by an enhanced chemiluminescence detection system (ECL kit; GE Healthcare) with an image analyzer (LAS-1000; Fuji Photo Film).

\section{ELISA}

The $P$. gingivalis infected leptomeningeal cells medium was collected at indicated time points and used IL-1 $\beta$ enzyme-linked immunosorbent assay (R\&D Systems) to measure the released IL-1 $\beta$ following the protocol provided by the manufacturer. The absorbency at 450 was measured using a microplate reader.

\section{Statistical analyses.}

The data are represented as the means \pm SEM. The statistical analyses were performed by a student's ttest and correlation using the GraphPad Prism software package (GraphPad Software, California, USA). A value of $p<0.05$ was considered to indicate statistical significance.

\section{Results}

\section{Systemic $P$. gingivalis infection induced increased IL-1 $\beta$ in leptomeninges and decreased synaptic marker in leptomeninges proximity cortex, accompanied memory decline in the middle-aged mice.}

To test our hypothesis that leptomeningeal cell-induced neuroinflammation might be involved in synaptic failure by releasing soluble factors during $P$. gingivalis infection, we firstly examined the expression of IL$1 \beta$ and SYP in the proximity of leptomeninges using the middle-aged mice (fifteen-month-old, female) which were used in our previous studies [14,34]. The time course of systemic infection with $P$. gingivalis was shown as an illustration (Fig. 1A). Compared with the control mice, the mice significantly reduced the latency in middle-aged mice after systemic infection with $P$. gingivalis for 3 weeks (Fig. 1B). However, no different of body weight was found between control mice and the P. gingivalis-infected ones (Fig. 1C), suggesting that the systemic $P$. gingivalis infection-induced learning and memory deficits in the middleaged mice are not associated with sickness behaviors. We next focused on expression of IL-1 $\beta$ in the leptomeninges, because IL-1 $\beta$ is the master mediator for inducting neuroinflammation $[13,21]$. Compared with the control mice, the IL-1 $\beta$ immunoreactivity was significantly increased in the fibronectin positive leptomeningeal cells of the $P$. gingivalis infected mice ( 7.5 -folds), demonstrating that IL-1 $\beta$ was induced in leptomeningeal cells in the middle-aged mice after systemic $P$. gingivalis infection (Fig. 1D, E). Compared with the control mice, the SYP immunoreactivity was significantly decreased (2.18-folds) in the cortex proximity of the leptomeninges in the middle-aged mice after systemic $P$. gingivalis infection (Fig. 1F, G). The expression of IL-1 $\beta$ was negative correlated with that of SYP in the systemic $P$. gingivalisinfected mice (Fig. $1 \mathrm{H})$. These observations evidenced that upregulated IL-1 $\beta$ in leptomeningeal cells, 
downregulated of synaptic marker and memory decline are induced in the middle-aged mice after systemic $P$. gingivalis infection.

\section{NLRP3 inflammasome involved in IL-1 $\beta$ secretion by primary leptomeningeal cells after $P$. gingivalis infection}

Next, the mechanisms underlying the involvement of $P$. gingivalis in IL-1 $\beta$ production were studied using primary leptomeningeal cells. To determine the appropriate concentration of living $P$. gingivalis on primary leptomeningeal cells, we first examined the cell viability of primary leptomeningeal cells infected by $P$. gingivalis at a multiplicity of infection (MOI) of 1,5 or 10 . The time course of in vitro experiments was set at up to $12 \mathrm{~h}$ after $P$. gingivalis infection, as $P$. gingivalis can be kept alive for up to $12 \mathrm{~h}$ in our cellular models $[14,34]$.

Compared with the start culture time $(0 \mathrm{~h})$, the cell viability of the primary leptomeningeal cells was not decreased up to $12 \mathrm{~h}$ at MOls of 1, 5 or 10 following $P$. gingivalis infection (Fig. 2A). Therefore, a MOI of 10 was used in subsequent experiments. We focused on IL-1 $\beta$ production by leptomeningeal cells after $P$. gingivalis infection, as in addition to being the master neuroinflammation regulator, IL-1 $\beta$ exerts direct effects on neurons $[16,35]$. Compared with the cells at $0 h$, the secretion of IL-1 $\beta$ by leptomeningeal cells was significantly increased from $1 \mathrm{~h}$ (10.7-fold), peaked at $3 \mathrm{~h}(21.8$-fold) and was reduced from 6 to $12 \mathrm{~h}$ after $P$. gingivalis infection (Fig. 2B).

We next examined the involvement of NLRP3 inflammasome in IL-1 $\beta$ production by leptomeningeal cells after $P$. gingivalis infection, as NLRP3 inflammasome activation can be detected during Gram-negative bacteria infection [36]. Compared with $0 \mathrm{~h}$, the mRNA expression of NLRP3 and Caspase-1 was significantly increased in the leptomeningeal cells from $1 \mathrm{~h}$ (4.3-fold, 1.6 -fold), continued at $3 \mathrm{~h}$ ( 6.5 -fold, 2.9-fold) and $6 \mathrm{~h}$ (6.9-fold, 3.8-fold) and lasted until $12 \mathrm{~h}$ (6.3-fold, 2.7-fold) after $P$. gingivalis infection (Fig. 2C, D).

To confirm the involvement of NLRP3 inflammasome in IL-1 $\beta$ production in leptomeningeal cells after $P$. gingivalis infection, we used siRNA to interfere with the NLRP3 mRNA expression. Compared with the control cells, the mRNA expression of NLRP3 was reduced by pretreatment with NLRP3 siRNA in both uninfected cells (49\% reduced) and $P$. gingivalis-infected cells (68\% reduced) (Fig. 2E). The protein expression of caspase-1 and IL-1 $\beta$ was also examined. Compared with the control cells, the protein expression of pro-caspase- 1 and maturate caspase- 1 was significantly increased in the leptomeningeal cells at $3 \mathrm{~h}$ after $P$. gingivalis infection (1.3-fold and 1.6-fold) and significantly decreased by NLRP3 siRNA (by $29 \%$ and $30 \%$ ), respectively (Fig. $2 \mathrm{~F}-\mathrm{H}$ ). Compared with the control cells, the protein expression of pro$\mathrm{IL}-1 \beta$ and mature IL-1 $\beta$ was significantly increased in the leptomeningeal cells at $3 \mathrm{~h}$ after $P$. gingivalis infection (2.6-fold, 5 -fold) and significantly decreased by NLRP3 siRNA (by $26 \%$ and $18 \%$ ), respectively (Fig. 2I-K). The $P$. gingivalis infection-induced increase in the secretion of IL-1 $\beta$ was significantly reduced by NLRP3 siRNA ( $28 \%$ reduced) (Fig. 2L). These observations showed that NLRP3 inflammasome involved in IL-1 $\beta$ secretion by leptomeningeal cells after $P$. gingivalis infection. 


\section{CatB is involved in NLRP3 inflammasome activation for IL-1 $\beta$ secretion by primary leptomeningeal cells after $P$. gingivalis infection}

We next examined the involvement of CatB in NLRP3 inflammasome activation in primary leptomeningeal cells after $P$. gingivalis infection, as CatB is required for NLRP3 inflammasome activation, resulting in IL-1 $\beta$ secretion $[20,21]$. Compared with the control cells, fluorescent-labeled $P$. gingivalis was detected in the lysosome-associated membrane protein 2(LAMP2)-positive lysosomes in leptomeningeal cells at $1 \mathrm{~h}$ after $P$. gingivalis infection, and the prevalence of fluorescent-labeled $P$. gingivalis in the lysosomes was reduced by pre-treatment with cytochalasin D (Cyto D), a specific phagocytosis inhibitor. These findings show that $P$. gingivalis can be phagocytosed into lysosomes in leptomeningeal cells after infection (Fig. 3A). Compared with the control cells, the punctate acridine orange aggregates had disappeared by $2 \mathrm{~h}$ after $P$. gingivalis infection, showing that lysosomal damage was induced in leptomeningeal cells after living $P$. gingivalis was phagocytized (Fig. 3B).

To further confirm the leakage of CatB from the damaged lysosomes, the protein expression of CatB in the cytosol was examined using the cytosol fraction of $P$. gingivalis-infected leptomeningeal cells. Compared with the control cells, the protein expression of CatB in the cytosol was significantly increased (1.5-fold) at $2 \mathrm{~h}$ after $P$. gingivalis infection (Fig. 3C, D). The involvement of cytosol leakage of CatB in NLRP3 inflammasome activation was then examined. Compared with the control cells, the protein expression of pro-caspase- 1 and mature-caspase- 1 was significantly increased at $3 \mathrm{~h}$ after $P$. gingivalis infection (1.3-fold, 1.8-fold), and pre-treatment with CA-074Me, the CatB specific inhibitor, significantly decreased the pro-caspase- 1 and mature-caspase-1 (by $61 \%$ and $20 \%$, respectively) (Fig. 3E-G) and the $P$. gingivalis-induced increase in IL-1 $\beta$ secretion from the leptomeningeal cells (by $50 \%$ ) (Fig. $3 \mathrm{H}$ ).

The effect of phagocytosed $P$. gingivalis on IL-1 $\beta$ secretion was further examined. Compared with the $P$. gingivalis infected cells, pre-treatment with Cyto $D$ significantly inhibited the $P$. gingivalis-upregulated protein expression of mature IL-1 $\beta$ (by 53\%) but not that of pro-IL-1 3 (Fig. 3I-K) and the P. gingivalisupregulated secretion of IL-1 $\beta$ from the leptomeningeal cells (by 70\%) (Fig. 3L). These observations showed that the cytosol leakage of CatB activated NLRP3 inflammasomes, which was required for the secretion of IL-1 $\beta$ by leptomeningeal cells after $P$. gingivalis infection.

\section{CatB is involved in NF-KB activation for IL-1 $\beta$ production by primary leptomeningeal cells after $P$. gingivalis infection}

CatB plays a critical role in nuclear factor kappa B (NF-kB) activation $[13,14,37]$. We therefore examined the involvement of CatB in NF-KB activation in leptomeningeal cells after $P$. gingivalis infection. Compared with the cells at $0 \mathrm{~h}$, the mRNA expression of toll-like receptor 2 (TLR2) was significantly increased from $1 \mathrm{~h}$ (1.7-fold), lasting through 3,6 and $12 \mathrm{~h}$ (5.2-fold, 5.2-fold, 3.3-fold, respectively) in the leptomeningeal cells after $P$. gingivalis infection (Fig. 4A). Compared with the cells at $0 \mathrm{~h}$, the mRNA expression of CatB was significantly increased from $1 \mathrm{~h}$ (1.7-fold), lasting through to 3,6 and $12 \mathrm{~h}(1.2-$ fold, 2.0-fold, 1.2-fold, respectively) in the leptomeningeal cells after $P$. gingivalis infection (Fig. 4B). To confirm the involvement of CatB in NF-KB activation in leptomeningeal cells, we next examined the 
protein expression of CatB from the early time before the peak of IL-1 $\beta$ secretion in leptomeningeal cells after $P$. gingivalis infection. Compared with the cells at $0 \mathrm{~h}$, the protein expression of CatB was significantly increased from $0.5 \mathrm{~h}$ (1.31-fold), lasting through to 1, 2 and $3 \mathrm{~h}$ (1.12-fold, 1.12-fold, 1.33fold, respectively) after $P$. gingivalis infection (Fig. 4C, D). In contrast, the protein expression of the nuclear factor of kappa light polypeptide gene enhancer in B-cells inhibitor alpha (IKBa) was significantly decreased at $1 \mathrm{~h}$ after $P$. gingivalis infection (by 24\%) compared with the cells at $0 \mathrm{~h}$, and the decrease in IKBa was significantly inhibited by pre-treatment with CA-074Me (by 58\%) (Fig. 4E, F).

We further examined the involvement of CatB in the expression of molecules downstream of NF-KB activation. The $P$. gingivalis infection-induced increase in the mRNA expression of NLRP3, Caspase- 1 and IL-1 $\beta$ was significantly inhibited by pre-treatment with CA-074Me in the leptomeningeal cells (by $55 \%, 87 \%$ and $66 \%$, respectively) (Fig. 4G-I). Moreover, the $P$. gingivalis-induced increase in protein expression of both pro-IL-1 $\beta$ and mature IL-1 $\beta$ was significantly inhibited by pre-treatment with CA-074Me in leptomeningeal cells (by $24 \%$ and $78 \%$, respectively) (Fig. 4J-L). These observations showed that CatB was involved in NF-KB activation, which is required for the production of NLRP3 and IL-1 $\beta$ in the leptomeningeal cells after $P$. gingivalis infection.

\section{P. gingivalis -infected leptomeningeal cells induced IL-1 $\beta$-dependent synaptic molecule loss in neurons}

As leptomeningeal cells anatomically cover the cortex of the brain, we developed a cellular model to investigate the direct influence of $P$. gingivalis-infected leptomeningeal cells on cortical neurons. Conditioned medium from $P$. gingivalis-infected leptomeningeal cells ( $3 \mathrm{~h}$ after $P$. gingivalis infection) was collected $(P g \mathrm{LCM})$ and applied to primary cultured cortical neurons. As we focused on the outcomes of $P$. gingivalis-infected leptomeningeal cells in neurons at the synaptic level, we first established the conditions of $P g$ LCM for the culture of primary cortical neurons. Compared with the control neurons, the cell viability of the primary cortical neurons was not reduced by applying $30 \% P g$ LCM for $24 \mathrm{~h}$ (Fig. 5A), although the mean neurite length was significantly reduced by the $P g$ LCM (by $38 \%$ ), showing that the morphological features of primary cortical neurons were changed by the $P g \mathrm{LCM}$ without inducing neuron death (Fig. 5B, C). Therefore, 30\% Pg LCM was used in the subsequent experiments.

We examined the pre- and post-synaptic protein levels because synaptic deficit is reversible neuronal damage and an early sign of AD. Compared with control neurons, the mRNA expression of pre-synaptic markers, synaptophysin (SYP), vesicular glutamate transporter1(VGLUT1) and synapsin1 (SYN1) as well as the post-synaptic marker postsynaptic density protein 95 (PSD95) was significantly decreased by the $P g$ LCM in primary cortical neurons (by 57\%,73\%, 44\% and 50\%, respectively) (Fig. 5D), and the $P g$ LCMinduced reduction in SYP was significantly and positively correlated with that in VGLUT1 $(r=0.9683, p=$ 0.0015) (Fig. 5E). We next analyzed the relationship between the secreted IL-1 $\beta$ in the $P g$ LCM and synaptic markers in the $P g$ LCM-applied primary cortical neurons. The mRNA expression of SYP, VGLUT1, SYN1 and PSD 95 in the $P g$ LCM-applied primary cortical neurons was significantly and negatively correlated with the concentration of IL-1 $\beta$ in Pg LCM ( $r=-0.8635, p=0.0267 ; r=-0.8628, p=0.0270$; $r=-0.9066, p=0.0127$ and $r=-0.8997, p=0.0146$, respectively) (Fig. 5F). The protein expression of SYP was 
further examined. Compared with control neurons, the protein expression of SYP was dramatically decreased by the $P g$ LCM (by 65\%) in the primary cortical neurons which was significantly inhibited by pre-treatment with NLRP3 siRNA or CA-074 Me in leptomeningeal cells (by 15\%, 52\%) (Fig. 5G, H). The Pg LCM-induced reduction in the protein expression of SYP in primary cortical neurons was dramatically inhibited by pre-treatment with IL-1 receptor antagonist (IL-1Ra) in neurons (by 69\%) (Fig. 5I, J). These observations showed that leptomeningeal cells induced soluble IL-1 $\beta$-dependent synaptic distribution after $P$. gingivalis infection.

\section{P. gingivalis -infected leptomeningeal cells induced the IL-1 $\beta$-dependent suppression of BDNF signaling in neurons}

To further explore the effect of IL-1 $\beta$ secreted by $P$. gingivalis-infected leptomeningeal cells on neurons, we focused on the effects of $P g$ LCM on BDNF signaling in neurons using stable mouse N2a cells [38].

We first examined the BDNF-induced expression of activity-regulated cytoskeleton-associated protein (Arc), a critical immediate early gene that plays an essential role in synaptic plasticity of neurons [39]. Compared with the start culture time ( $0 \mathrm{~min})$, the mRNA expression of Arc was induced from $10 \mathrm{~min}$ (4fold), peaked at $30 \mathrm{~min}$ (5.3-fold), continued through $60 \mathrm{~min}$ and lasted until $120 \mathrm{~min}$ (3-fold, 2-fold, respectively) in N2a cells after pre-treatment with BDNF, and the BDNF-induced Arc expression at 30 min was dramatically reduced by pre-treatment with Pg LCM (by 76\%) (Fig. 6A).

Next, we examined the effect of IL-1 $\beta$ in $P g$ LCM on activation of protein kinase B/cAMP response element binding protein (Akt/CREB), the molecules of BDNF signaling. Compared with control cells, pretreatment with BDNF for $2 \mathrm{~h}$ significantly increased the Akt phosphorylation at Ser473 (1.2-fold), and the BDNF-induced increase in Akt phosphorylation was significantly decreased by pre-treatment with $P g$ LCM (by 58\%) (Fig. 5B, C). The Pg LCM-induced decrease in Akt phosphorylation was significantly reversed by pre-treatment with IL-1Ra (by 13\%) (Fig. 6B, C).

We next examined the activation of CREB, a transcription factor downstream of Akt phosphorylation. Compared with control cells, pre-treatment with BDNF for $2 \mathrm{~h}$ significantly increased the CREB phosphorylation at Ser133 (1.2-fold), and the BDNF-induced increase in CREB phosphorylation was significantly decreased by pre-treatment with $P g$ LCM (by 15\%). The $P g$ LCM-induced decrease in CREB phosphorylation was significantly reversed by pre-treatment with IL-1Ra (by 82\%) (Fig. 6D, E).

In addition, the nuclear localization of phosphorylated CREB, which represents the activation of CREB, was also examined. Compared with control cells, the nuclear localization of phosphorylated CREB was significantly increased at $4 \mathrm{~h}$ in the BDNF pre-treated N2a cells (4.8-fold), and the BDNF-induced increase in CREB nuclear localization was significantly decreased by pre-treatment with $P g$ LCM (by $84 \%)$. The $P g$ LCM-induced decrease in CREB nuclear localization was significantly reversed by pre-treatment with IL1Ra (by 40\%) (Fig. 6F, G). 
Taken together, these observations showed that $P$. gingivalis-infected leptomeningeal cells induced the IL$1 \beta$-dependent suppression of BDNF signaling in neurons.

\section{Propolis modulated the IL-1 $\beta$-related BDNF production by primary leptomeningeal cells after $P$. gingivalis infection}

As structures covering the surface of the brain, leptomeningeal cells are known to protect neurons by producing neuroprotective factors. We therefore explored the involvement of IL-1 $\beta$ in the production BDNF, a critical neurotrophic factor, by leptomeningeal cells after $P$. gingivalis infection.

Compared with the cells at $0 \mathrm{~h}$, the mRNA expression of BDNF and IL-1 $\beta$ was significantly increased from $1 \mathrm{~h}$ (8.7-fold, 8.5-fold) to $3 \mathrm{~h}$ (14-fold, 62-fold), respectively (Fig. 7A, B) in the leptomeningeal cells after $P$. gingivalis infection. We further explored the potential utility of natural materials for moderating the production of IL-1 $\beta$ and BDNF in P. gingivalis-infected leptomeningeal cells. To this end, we focused on propolis, which was shown to prevent cognitive decline in elderly subjects [33]. The cell viability was examined to determine the suitable condition of propolis for primary leptomeningeal cells. Compared with control cells, the cell viability was not significantly decreased until pre-treatment with propolis at $10 \mu \mathrm{g} / \mathrm{ml}$ (Fig. 7C), so $10 \mu \mathrm{g} / \mathrm{ml}$ of propolis was used in the following experiments. To our surprise, compared with the $P$. gingivalis-infected cells, the expression of BDNF was significantly increased (by $28 \%$ ) while that of IL-1 $\beta$ was markedly decreased (by $78 \%$ ) in the $P$. gingivalis-infected cells following pretreatment with propolis (Fig. 7D, E). The mRNA expression of BDNF was significantly and negatively correlated with the IL-1 $\beta$ mRNA expression in leptomeningeal cells $(r=-0.8968, p=0.0154)$ (Fig. 7F). Compared with the $P$. gingivalis-infected cells, the mRNA expression of CatB in the $P$. gingivalis-infected leptomeningeal cells was significantly decreased by pre-treatment with propolis (by $40 \%$ ) (Fig. 7G), which paralleled the findings of NLRP3 and Caspase-1 (20\% and 24\% decrease) (Fig. S1). The propolis-induced reduction in the mRNA expression of NLRP3 and Caspase-1 was significantly and positively correlated with that of CatB in the $P$. gingivalis-infected leptomeningeal cells $(r=0.9343, p=0.0063 ; r=0.9882, p=$ 0.0002 , respectively) (Fig. S2). In contrast, the CatB mRNA expression was positively correlated with IL-1 $\beta$ but negatively correlated with BDNF mRNA (Fig. 7H, I).

Taken together, these observations showed that BDNF production was downregulated by the CatBmediated IL-1 $\beta$ upregulation in leptomeningeal cells after $P$. gingivalis infection, and propolis upregulated BDNF by inhibiting IL-1 $\beta$ in leptomeningeal cells after $P$. gingivalis infection.

\section{Discussion}

The major findings of the present study were our determination using our established mouse and cellular models that the leptomeningeal cell-induced synaptic failure by CatB/NLRP3 inflammasomes mediated IL-1 $\beta$ production during $P$. gingivalis infection (Summarized in Fig. 8). To our knowledge, this is the first study showing the involvement of leptomeningeal cells in the earliest signs before AD onset during $P$. gingivalis infection, thus providing a new mechanism underlying the involvement of periodontal bacterial infection in the initiation and pathological processes of AD. 
As structures covering the surface of brain, leptomeningeal cells are recognized as an interface between the systemic circulation and the brain $[22,23]$. In the present study, the significantly increase of IL-1 $\beta$ in the fibronectin-positive leptomeningeal cells in the middle-aged mice after systemic $P$. gingivalis infection (7.5-folds), suggesting leptomeningeal cells is the important source of IL-1 $\beta$ for inducting neuroinflammation during systemic inflammation $[22,23,27]$. The secretion of IL-1 $\beta$ by leptomeningeal cells was detected as soon as $1 \mathrm{~h}$ (10.7-fold) and peaked at $3 \mathrm{~h}$ (21.8-fold) after $P$. gingivalis infection, indicating that leptomeningeal cells sensitively respond to $P$. gingivalis infection, similar to other bacteria [40]. The IL-1 $\beta$ secretion by $P$. gingivalis infected-leptomeningeal cells was mediated by NLRP3 inflammasome activation, as the $P$. gingivalis-induced IL- $1 \beta$ secretion was accompanied by the increased NLRP3 expression, and single siRNA reduced the NLRP3 mRNA expression by half ( $49 \%-68 \%$ ), resulting in a significant reduction in the mature caspase- 1 and IL- $1 \beta$ protein levels as well as the IL-1 $\beta$ secretion (Fig. 1). These observations of NLRP3 inflammasome activation-dependent IL-1 $\beta$ production by $P$. gingivalis-infected leptomeningeal cells were consistent with those of other cells in response to $P$. gingivalis $[18,19]$. The rapid release of IL-1 $\beta$ by $P$. gingivalis-infected leptomeningeal cells indicate that the interface cells between circulation and the brain may as an early inflammatory source directly act on neurons in addition to inducing neuroinflammation during $P$. gingivalis infection $[14,25]$.

CatB, a cysteine lysosomal protease, is known to be involved in NLRP3 inflammasome activation [20]. Our present observations show that $P$. gingivalis phagocytosis and subsequent lysosomal damage results in leakage of CatB into the cytosol of leptomeningeal cells. The significant inhibition of Cyto $D, a$ special inhibitor of phagocytosis, against the $P$. gingivalis-induced upregulation of IL-1 $\beta$ secretion, indicates that phagocytosis of $P$. gingivalis is required for IL-1 $\beta$ production. This is consistent with the effects of phagocytosis on IL-1 $\beta$ production $[20,21]$.The significant inhibition of CA-074Me, a special inhibitor of CatB, on the upregulation of the expression of mature caspase-1 protein, as well as IL-1 $\beta$ secretion by $P$. gingivalis-infected leptomeningeal cells, demonstrate that CatB is involved in the IL-1 $\beta$ secretion by leptomeningeal cells after $P$. gingivalis infection via the induction of caspase- 1 activation $[20,21]$. Of note, the inhibitory rate of IL- $1 \beta$ secretion by CA- $074 \mathrm{Me}$ was more than that by Cyto $D$ ( $49 \%$ vs. $31 \%)$, suggesting additional effects of CatB on the secretion of IL-1 $\beta$ by leptomeningeal cells after $P$. gingivalis infection.

CatB is known to be involved in the TLR-mediated NF-KB activation [14, 21, 37]. In the present study, the increase in CatB occurred at an earlier point than the decrease in $1 \mathrm{kBa}$ (endogenous NF-KB inhibitor) in the $P$. gingivalis-infected leptomeningeal cells, and the $P$. gingivalis-induced decrease in IKBa was significantly reversed by $\mathrm{CA}-074 \mathrm{Me}$, indicating that CatB promotes early NF-KB activation by inducing IKBa degradation in leptomeningeal cells during $P$. gingivalis infection. The effects of CatB on degrading IKBa for NF-KB activation were supported by the findings of previous reports in other brain cells $[14,37]$. The CatB-NF-KB positive feedback loop may further accelerate NF-KB activation in leptomeningeal cells during $P$. gingivalis infection, as the CatB promoter contains NF-KB binding sites [41]. The significant inhibition of CA-074 Me on the expression of NLRP3, caspase-1 and IL-1 $\beta$ indicated that CatB-involved NF-KB activation contributes to IL-1 $\beta$ production by leptomeningeal cells after $P$. gingivalis infection, as the promoters of NLRP3 and IL-1 $\beta$ have NF-KB binding sites [42, 43], and NF-KB activation is sufficient to 
induce pro-caspase-1 [44]. Of note, the inhibitory effects of CA-074 Me on mature IL-1 $\beta$ were stronger than those on NLRP3 and pro-IL-1 $\beta$ (78\%, 55\% and $66 \%$ reduction, respectively), suggesting that CatB may be involved in IL-1 $\beta$ production by $P$. gingivalis-infected leptomeningeal cells by activating caspase- 1 in the lysosomal pathway [20,21].

Taken together, these findings suggest that CatB is involved in IL-1 $\beta$ secretion in several ways, including by inducing the activation of NLRP3 inflammasome, NF-KB and caspase-1 in leptomeningeal cells after $P$. gingivalis infection.

The IL-1 $\beta$ secreted by $P$. gingivalis-infected leptomeningeal cells may directly influence cortical neurons, as leptomeningeal cells anatomically cover the surface of the brain. We focused on synaptic molecules in neurons as an outcome of $P$. gingivalis-induced IL- $1 \beta$ in our cellular models, as synapse degeneration is the earliest sign before the onset of $A D[1,2]$, and synaptic pathology is present in the cortex of $A D$ patients with severe cognitive decline [1]. The major presynaptic vesicle proteins, including SYP, SYN1 and VGLUT1, were used to evaluate presynaptic generation, as a reduction in SYP is considered to reflect a reduction in the distribution of synapses in the brain [45], and VGLUT1 is known to determine the amount of glutamatergic transmission [46], while a reduction in SYN1 induces the early disruption of synaptic generation, as it regulates the availability of synaptic vesicles and synaptic transmission [47]. PSD-95 was selected for evaluating the post-synaptic generation, as it is a scaffold protein localized in postsynaptic terminals and interacts with glutamate receptors (NMDA type) [48]. In the present study, the 7.5-folds increased IL- $1 \beta$ in the leptomeningeal cells was negatively correlated with 2.18 -folds decreased SYP in the cortex proximity of the leptomeningeal cells in the P. gingivalis-infected mice (Fig. 1), suggesting the IL-1 $\beta$ from $P$. gingivalis-infected leptomeningeal cells may directly influence cortical neuron, because leptomeningeal cells anatomically cover the surface (cortex) of the brain. In the primary cortical neurons, the mRNA expression of SYP, SYN1 and VGLUT1 as well as PSD95 in the primary cortical neurons was dramatically reduced by treatment with $\mathrm{Pg}$ LCM (by $57 \%, 44 \%, 73 \%$ and $50 \%$, respectively) without inducing neuron death (Fig. 4), indicating that $P g$ LCM negatively impacts both preand post-synaptic generation. The overlapping reduction in VGLUT1 and SYP induced by Pg LCM showed a positive correlation (Fig. $4 \mathrm{H}$ ), suggesting that $P g$ LCM induced synaptic degeneration, as SYP is mainly associated with VGLUT1-positive synaptic ends, and the concentration of VGLUT1 in the prefrontal cortex has been used as an early marker of cognitive decline clinically, since a marked loss of VGLUT1 in the prefrontal cortex of AD patients significantly reduces the intensity of glutamatergic transmission and causes devastating consequences for the cognitive function [4]. In addition, regarding their functional localization in presynaptic vesicles, the simultaneous reduction in SYP, SYN1 and VGLUT1 accelerated the presynaptic distribution, and synaptic transmission may accelerate cognitive decline in AD patients [45], as the mRNA levels of SYP and SYN1 were significantly decreased (by roughly $40 \%$ and $30 \%$, respectively) in the brains of $\mathrm{MCl}$ patients, which increases the risk of developing $A D$. Of note, the expression of SYP, SYN1, VGLUT1 and PSD-95 in primary cortical neurons was strongly and negatively correlated with the concentration of IL-1 $1 \beta$ in the $P g$ LCM, and the $P g$ LCM-induced SYP reduction in the protein level was dramatically prevented by IL-1Ra (by $69 \%$, Fig. 4), strongly suggesting that IL-1 $\beta$ is the 
major soluble factor in $\mathrm{Pg}$ LCM for inducing synaptic degeneration. These results are consistent with other studies showing the involvement of IL-1 $\beta$ in downregulating synaptic molecules [39].

BDNF signaling is a major regulator of synaptic generation and plasticity $[5,6]$. In the present study, we further demonstrated that $P g$ LCM significantly suppressed the BDNF-induced Arc expression in neurons (by 76\%), the common marker of synaptic plasticity [39]via Akt/CREB signaling [49]. The Pg LCM reduced the BDNF-induced Akt phosphorylation (Ser473, by $58 \%$ ), which was significantly reversed by pretreatment with IL-Ra. This suggests that $P g$ LCM-IL-1 $\beta$ mediated the suppression effects of $P g$ LCM on BDNF-induced Akt phosphorylation. At the same time, $P g$ LCM reduced the BDNF-induced nuclear localization of phosphorylated CREB, downstream of Akt phosphorylation. This effect was significantly reversed by pretreatment with IL-Ra. Taken together, these observations suggest that $P$. gingivalis-induced IL-1 $\beta$ production by leptomeningeal cells mediates the suppression of synaptic plasticity by interfering with BDNF signaling cascades. The Pg LCM IL-1ß-induced reduction in CREB activation may also contribute to its downregulating effects on synaptic proteins, as SYP, SYN1 and PSD 95 can be regulated by CREB activation [39]. Furthermore, synaptic proteins, including SYN1 and PSD95, are involved in synaptic plasticity [50]. Therefore, the $P$. gingivalis-induced production of IL-1 $\beta$ by leptomeningeal cells directly induces negative feedback on synaptic generation and plasticity.

In the present study, the BDNF expression rapidly increased in leptomeningeal cells, as early as $1 \mathrm{~h}$ after $P$. gingivalis infection (8.7-fold), showing that leptomeningeal cells can functionally protect neurons during $P$. gingivalis infection in the early period. However, of note, the increase in IL-1 $\beta$ at $3 \mathrm{~h}$ (62-fold) was much higher than that of BDNF (14-fold) at the same time in leptomeningeal cells, demonstrating an imbalance between BDNF and IL-1 $\beta$ after $P$. gingivalis infection. This imbalance may contribute to a systemic $P$. gingivalis infection-induced reduction in the memory function, even in middle-aged mice (Fig. 1B), as continual IL-1 $\beta$ release increases the synaptic sensitivity to IL-1 [35].

Propolis, a resinous substance produced by honeybees, has been useful for reducing microglia-related inflammatory mediators, including IL-1 $\beta[25,30]$. Exceeding our expectations, propolis significantly increased the expression of BDNF (by $40 \%$ ) while dramatically decreasing that of IL-1 $\beta$ (by $79 \%$ ) in $P$. gingivalis-infected leptomeningeal cells, and the propolis-upregulated BDNF was negatively correlated with the propolis-downregulated IL-1 $1 \beta$, showing that propolis corrected the imbalance between IL-1 $\beta$ and BDNF in leptomeningeal cells during $P$. gingivalis infection. In contrast, propolis significantly reduced the expression of CatB in $P$. gingivalis-infected leptomeningeal cells, and the propolis-related reduction in CatB was positive correlated with that of IL-1 $\beta$ expression but negatively correlated with that of BDNF expression in P. gingivalis-infected leptomeningeal cells. In addition, since our previous results showed CatB plays critical roles in $P$. gingivalis/LPS-induced IL-1 $\beta$ production $[13,14,34]$, the propolis-modulated IL-1 $\beta$ and BDNF production may also be related to the effects of propolis on CatB expression (Fig. 6). These results suggest that the propolis-mediated prevention of the cognitive decline may depend in part on the regulation of the soluble factors by the leptomeningeal cells for synaptic maintenance $[25,33]$.

\section{Conclusions}


In summary, we showed that IL-1 $\beta$ secretion was induced in leptomeningeal cells though the CatBmediated activation of NLRP3 inflammasome and NF-KB after $P$. gingivalis infection, that the production of IL-1 $\beta$ by $P$. gingivalis-infected leptomeningeal cells induced synaptic failure, and that BDNF signaling in neurons was blocked. Propolis modulated the $P$. gingivalis infection-induced imbalance of IL-1 $\beta$ and BDNF production in leptomeningeal cells.

These findings highlight a new mechanism underlying the involvement of periodontitis in $A D$ initiation and suggest that CatB may be an early intervention therapeutic target for delaying the onset of $A D$ during $P$. gingivalis infection. Propolis may be useful as a nutraceutical approach to modulating IL-1 $\beta$ and BDNF production in $P$. gingivalis-infected leptomeningeal cells.

\section{List Of Abbreviations}

AD: Alzheimer's disease; Akt: protein kinase B; Arc: activity-regulated cytoskeleton-associated protein; BCSFB: blood-cerebrospinal fluid barrier; BDNF: brain-derived neurotrophic factor; CatB: cathepsin B; CNS: central nervous system; CREB: CAMP response element binding protein; CSF: cerebrospinal fluid; Cyto D: cytochalasin D; IKBa: inhibitor of nuclear factor kappa B; LAMP2: lysosome-associated membrane protein 2; LPS: lipopolysaccharide from Porphyromonas gingivalis; MCl: mild cognitive impairment; MOI: multiplicity of infection; NF-kB: nuclear factor kappa B; NLRP3: NOD-, LRR- and pyrin domain-containing protein 3; P. gingivalis: Porphyromonas gingivalis, Pg LCM: Porphyromonas gingivalis infected leptomeningeal cells condition medium; PSD95: postsynaptic density protein 95; SYN1: synapsin1; SYP: synaptophysin; TLR2: toll-like receptor 2; VGLUT1: vesicular glutamate transporter1

\section{Declarations}

\section{Ethics approval and consent to participate}

Not applicable

\section{Consent for publication}

Not applicable.

\section{Availability of data and materials}

The data used in this study are available from the corresponding authors up on reasonable request.

\section{Competing interest}

The authors declare that they have no competing interests.

\section{Funding}


This work was supported by funding from Grants-in-Aid for Scientific Research, Japan (16K11478 to Z.W), the research grant for OBT research center from Kyushu University (to Z.W) and Beijing Institute of Technology Research Fund Program for Young Scholars to J.N (2020CX04166).

\section{Authors' contribution}

W.H. conducted most of the experiments, analyzed the data and wrote the manuscript. F.Z., Y.G and M.J. analyzed the data. X.Z and X.Y. provided valuable advices. T.K. provided unpublished reagents/analytic tools. S.M. and H.K. provided valuable advices. J.N. designed the study and wrote the manuscript. Z.W. designed and supervised the experiments, and wrote the manuscript. All authors read and approved the final manuscript.

\section{Acknowledgements}

Not applicable

\section{References}

1. Kordower JH, Chu Y, Stebbins GT, Dekosky ST, Cochran EJ, Bennett D, et al. Loss and atrophy of layer II entorhinal cortex neurons in elderly people with mild cognitive impairment. Ann Neurol. 2001; 49:202-13.

2. Selkoe DJ. Alzheimer's disease is a synaptic failure. Science. 2002; 789-91.

3. Counts SE, Alldred MJ, Che S, Ginsberg SD, Mufson EJ. Synaptic gene dysregulation within hippocampal CA1 pyramidal neurons in mild cognitive impairment. Neuropharmacology; 2014; 79:172-9.

4. Du X, Li J, Li M, Yang X, Qi Z, Xu B, et al. Research progress on the role of type i vesicular glutamate transporter (VGLUT1) in nervous system diseases. Cell Biosci. 2020; 1-10.

5. Bramham CR, Messaoudi E. BDNF function in adult synaptic plasticity: The synaptic consolidation hypothesis. Prog. Neurobiol. Pergamon; 2005; 99-125.

6. Fritsch B, Reis J, Martinowich K, Schambra HM, Ji Y, Cohen LG, et al. Direct current stimulation promotes BDNF-dependent synaptic plasticity: Potential implications for motor learning. Neuron. 2010; 66:198-204.

7. Bomba M, Granzotto A, Castelli V, Onofrj M, Lattanzio R, Cimini A, et al. Exenatide Reverts the HighFat-Diet-Induced Impairment of BDNF Signaling and Inflammatory Response in an Animal Model of Alzheimer's Disease. J Alzheimer's Dis. 2019; 70:793-810.

8. Kamer AR, Dasanayake AP, Craig RG, Glodzik-Sobanska L, Bry M, De Leon MJ. Alzheimer's disease and peripheral infections: The possible contribution from periodontal infections, model and hypothesis. J. Alzheimer's Dis. 2008; 437-49.

9. Ide M, Harris M, Stevens A, Sussams R, Hopkins V, Culliford D, et al. Periodontitis and Cognitive Decline in Alzheimer's Disease. Garg P, editor. PLoS One. 2016;11: e0151081. 
10. Hajishengallis G, Lamont RJ. Beyond the red complex and into more complexity: The polymicrobial synergy and dysbiosis (PSD) model of periodontal disease etiology. Mol Oral Microbiol.2012;27:409-19.

11. Poole S, Singhrao SK, Kesavalu L, Curtis MA, Crean SJ. Determining the presence of periodontopathic virulence factors in short-term postmortem Alzheimer's disease brain tissue. $\mathrm{J}$ Alzheimer's Dis. 2013; 36:665-77.

12. Dominy SS, Lynch C, Ermini F, Benedyk M, Marczyk A, Konradi A, et al. Porphyromonas gingivalis in Alzheimer's disease brains: Evidence for disease causation and treatment with small-molecule inhibitors. Sci Adv. 2019;5.

13. Wu Z, Ni J, Liu Y, Teeling JL, Takayama F, Collcutt A, et al. Cathepsin B plays a critical role in inducing Alzheimer's disease-like phenotypes following chronic systemic exposure to lipopolysaccharide from Porphyromonas gingivalis in mice. Brain Behav Immun. 2017; 65:350-61.

14. Zeng F, Liu Y, Huang W, Qing H, Kadowaki T, Kashiwazaki H, et al. Receptor for advanced glycation end products up-regulation in cerebral endothelial cells mediates cerebrovascular-related amyloid $\beta$ accumulation after Porphyromonas gingivalis J Neurochem. 2020; jnc.15096.

15. Gu Y, Wu Z, Zeng F, Jiang M, Teeling JL, Ni J, et al. Systemic Exposure to Lipopolysaccharide from Porphyromonas gingivalis Induces Bone Loss-Correlated Alzheimer's Disease-Like Pathologies in Middle-Aged Mice. J Alzheimer's Dis. 2020;1-14.

16. Mishra A, Kim HJ, Shin AH, Thayer SA. Synapse loss induced by interleukin-1 $\beta$ requires pre-and postsynaptic mechanisms. J Neuroimmune Pharmacol. 2012; 7:571-8.

17. Voet S, Srinivasan S, Lamkanfi M, Loo G. Inflammasomes in neuroinflammatory and neurodegenerative diseases. EMBO Mol Med. 2019;11.

18. Park E, Na HS, Song YR, Shin SY, Kim YM, Chung J. Activation of NLRP3 and AIM2 inflammasomes by Porphyromonas gingivalis Infect Immun. 2014; 82:112-23.

19. Okano T, Ashida H, Suzuki S, Shoji M, Nakayama K, Suzuki T. Porphyromonas gingivalis triggers NLRP3-mediated inflammasome activation in macrophages in a bacterial gingipains-independent manner. Eur J Immunol. 2018; 48:1965-74.

20. Halle A, Hornung V, Petzold GC, Stewart CR, Monks BG, Reinheckel T, et al. The NALP3 inflammasome is involved in the innate immune response to amyloid- $\beta$. Nat Immunol. 2008; 9:85765.

21. Wu Z, Sun L, Hashioka S, Yu S, Schwab C, Okada R, et al. Differential pathways for interleukin-1 $\beta$ production activated by chromogranin A and amyloid $\beta$ in microglia. Neurobiol Aging. 2013; 34:2715-25.

22. Wu Z, Zhang J, Nakanishi $\mathrm{H}$. Leptomeningeal cells activate microglia and astrocytes to induce IL-10 production by releasing pro-inflammatory cytokines during systemic inflammation. J Neuroimmunol. $2005 ; 167: 90-8$.

23. Wu Z, Tokuda Y, Zhang XW, Nakanishi H. Age-dependent responses of glial cells and leptomeninges during systemic inflammation. Neurobiol Dis. 2008; 32:543-51. 
24. Vernet-der Garabedian B, Lemaigre-Dubreuil Y, Mariani J. Central origin of IL-1 $\beta$ produced during peripheral inflammation: Role of meninges. Mol Brain Res. 2000; 75:259-63.

25. Liu Y, Wu Z, Zhang X, Ni J, Yu W, Zhou Y, et al. Leptomeningeal cells transduce peripheral macrophages inflammatory signal to microglia in reponse to Porphyromonas gingivalis Mediators Inflamm. 2013.

26. Kipnis J. Multifaceted interactions between adaptive immunity and the central nervous system. Science. 2016; 766-71.

27. Rua R, McGavern DB. Advances in Meningeal Immunity. Trends Mol. Med. 2018; 542-59.

28. King VR, Alovskaya A, Wei DYT, Brown RA, Priestley J V. The use of injectable forms of fibrin and fibronectin to support axonal ingrowth after spinal cord injury. Biomaterials. 2010; 31:4447-56.

29. Castaldo S, Capasso F. Propolis, an old remedy used in modern medicine. Fitoterapia. 2002; 73: S16.

30. Wu Z, Zhu A, Takayama F, Okada R, Liu Y, Harada Y, et al. Brazilian Green Propolis Suppresses the Hypoxia-Induced Neuroinflammatory Responses by Inhibiting NF-KB Activation in Microglia. Oxid Med Cell Longev. 2013:1-10.

31. Izuta H, Shimazawa M, Tazawa S, Araki Y, Mishima S, Hara H. Protective Effects of Chinese Propolis and Its Component, Chrysin, against Neuronal Cell Death via Inhibition of Mitochondrial Apoptosis Pathway in SH-SY5Y Cells. J Agric Food Chem. 2008; 56:8944-53.

32. Ni J, Wu Z, Meng J, Zhu A, Zhong X, Wu S, et al. The Neuroprotective Effects of Brazilian Green Propolis on Neurodegenerative Damage in Human Neuronal SH-SY5Y Cells. Oxid Med Cell Longev. $2017 ; 2017: 1-13$.

33. Zhu A, Wu Z, Zhong X, Ni J, Li Y, Meng J, et al. Brazilian Green Propolis Prevents Cognitive Decline into Mild Cognitive Impairment in Elderly People Living at High Altitude. J Alzheimer's Dis. 2018; 63:551-60.

34. Nie R, Wu Z, Ni J, Zeng F, Yu W, Zhang Y, et al. Porphyromonas gingivalis Infection Induces Amyloid- $\beta$ Accumulation in Monocytes/Macrophages. J Alzheimer's Dis. 2019;1-16.

35. Prieto GA, Snigdha S, Baglietto-Vargas D, Smith ED, Berchtold NC, Tong L, et al. Synapse-specific IL-1 receptor subunit reconfiguration augments vulnerability to IL-1 $\beta$ in the aged hippocampus. Proc Natl Acad Sci U S A. 2015; 112: E5078-87.

36. Broz P. Recognition of Intracellular Bacteria by Inflammasomes. Microbiol Spectr. 2019;7.

37. Ni J, Wu Z, Peterts C, Yamamoto K, Qing H, Nakanishi H. The critical role of proteolytic relay through cathepsins B and E in the phenotypic change of microglia/macrophage. J Neurosci. 2015; 35:12488-501.

38. Jiang M, Meng J, Zeng F, Qing H, Hook G, Hook V, et al. Cathepsin B inhibition blocks neurite outgrowth in cultured neurons by regulating lysosomal trafficking and remodeling. J Neurochem. 2020;300-12. 
39. Rosi S. Neuroinflammation and the plasticity-related immediate-early gene Arc. Brain. Behav. Immun. 2011.

40. Fowler MI, Weller RO, Heckels JE, Christodoulides M. Different meningitis-causing bacteria induce distinct inflammatory responses on interaction with cells of the human meninges. Cell Microbiol. 2004; 6:555-67.

41. Wang T, Lafuse WP, Zwilling BS. NF-KB and Sp1 Elements Are Necessary for Maximal Transcription of Toll-like Receptor 2 Induced by Mycobacterium avium. J Immunol. 2001; 167:6924-32.

42. Boaru SG, Borkham-Kamphorst E, Van De Leur E, Lehnen E, Liedtke C, Weiskirchen R. NLRP3 inflammasome expression is driven by NF-KB in cultured hepatocytes. Biochem Biophys Res Commun. 2015; 458:700-6.

43. Liu T, Zhang L, Joo D, Sun SC. NF-kB signaling in inflammation. Signal Transduct. Target. Ther. 2017; $1-9$.

44. Lee DJ, Du F, Chen SW, Nakasaki M, Rana I, Shih VFS, et al. Regulation and Function of the Caspase1 in an Inflammatory Microenvironment. J Invest Dermatol. 2015; 135:2012-20.

45. Minger SL, Honer WG, Esiri MM, Mcdonald B, Keene J, Nicoll JAR, et al. Synaptic pathology in prefrontal cortex is present only with severe dementia in Alzheimer disease. J Neuropathol Exp Neurol. 2001; 60:929-36.

46. Fremeau RT, VogImaier S, Seal RP, Edwards RH. VGLUTs define subsets of excitatory neurons and suggest novel roles for glutamate. Trends Neurosci. 2004; 98-103.

47. Mertens R, Melchert S, Gitler D, Schou MB, Saether SG, Vaaler A, et al. Epitope specificity of antisynapsin autoantibodies: Differential targeting of synapsin I domains. Meinl E, editor. PLoS One. 2018;13: e0208636.

48. Elias GM, Funke L, Stein V, Grant SG, Bredt DS, Nicoll RA. Synapse-Specific and Developmentally Regulated Targeting of AMPA Receptors by a Family of MAGUK Scaffolding Proteins. Neuron. 2006; 52:307-20.

49. Chen TJ, Wang DC, Chen SS. Amyloid- $\beta$ interrupts the PI3K-Akt-mTOR signaling pathway that could be involved in brain-derived neurotrophic factor-induced Arc expression in rat cortical neurons. $J$ Neurosci Res. 2009; 87:2297-307.

50. Hilfiker S, Benfenati F, Doussau F, Nairn AC, Czernik AJ, Augustine GJ, et al. Structural domains involved in the regulation of transmitter release by synapsins. J Neurosci. 2005; 25:2658-69.

\section{Figures}


A
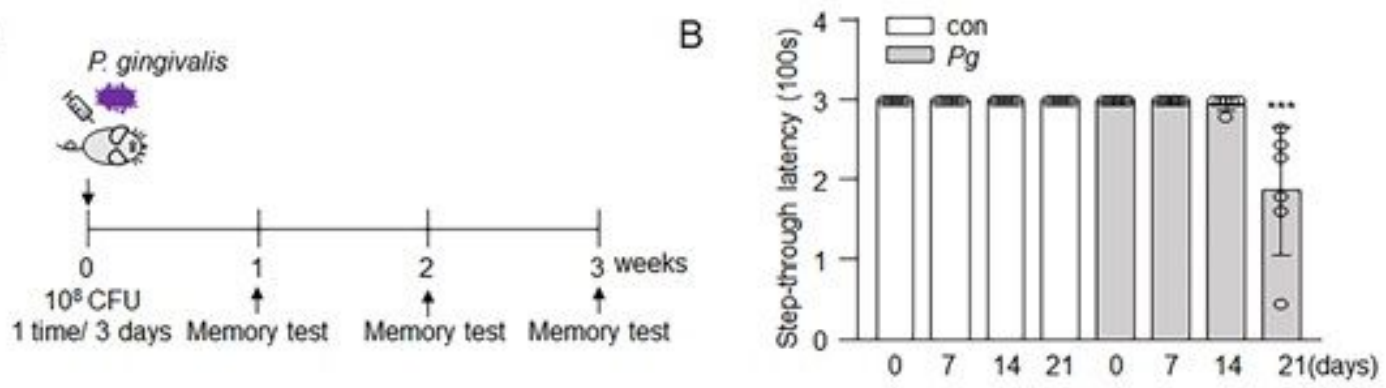

C
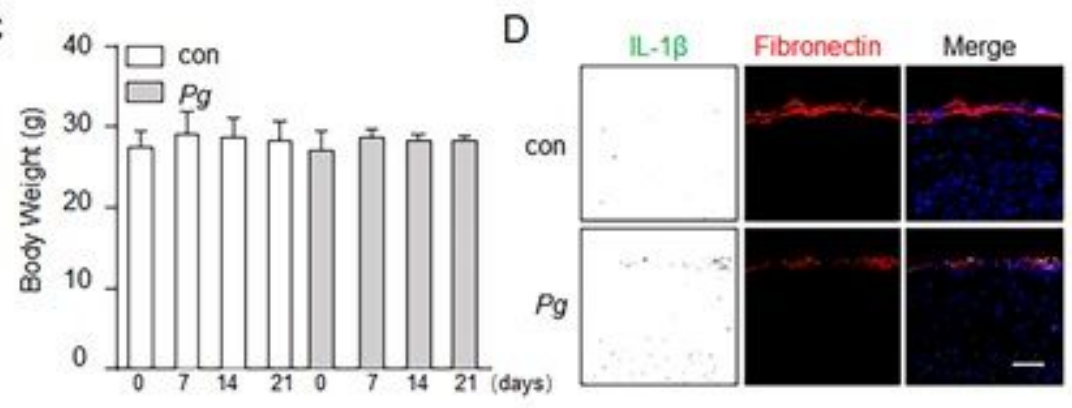

E

F

G

$\mathrm{H}$
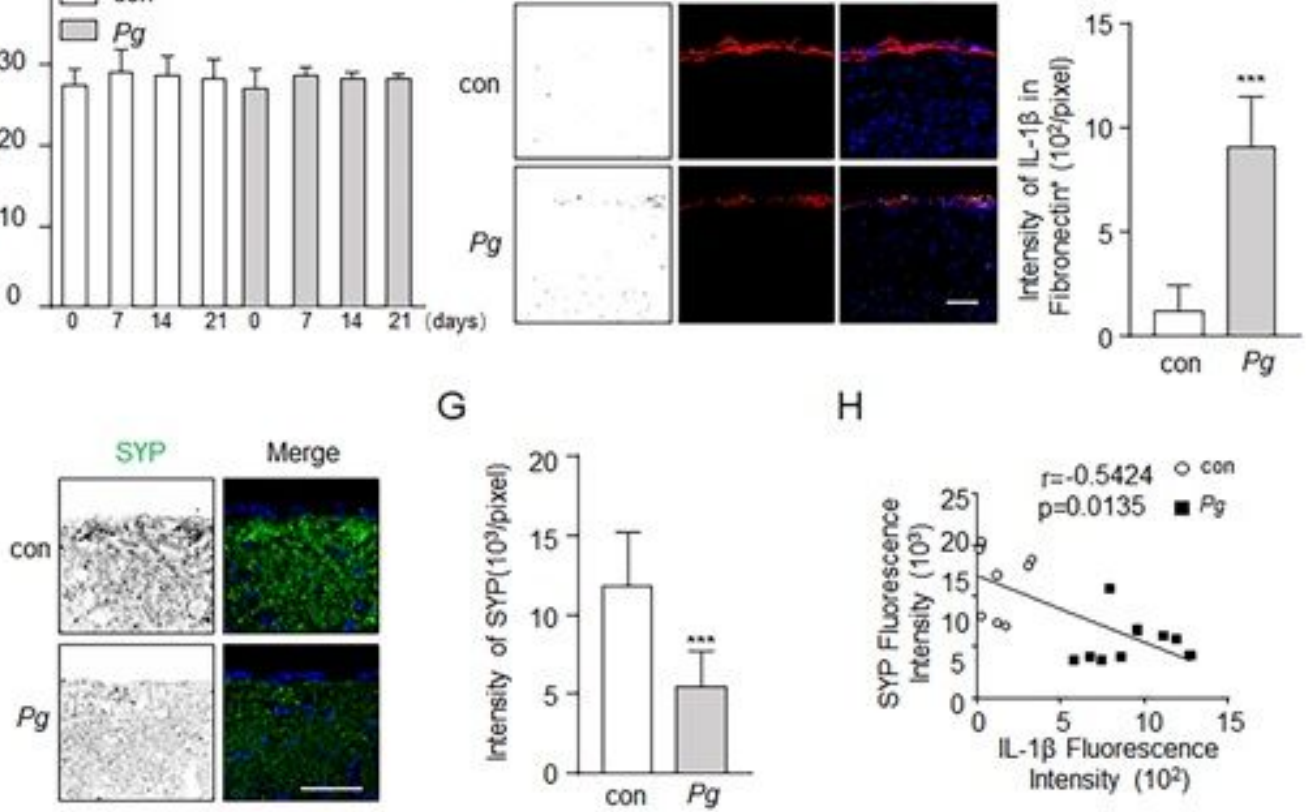

\section{Figure 1}

Increased IL-1 $\beta$ in leptomeninges and decreased synaptic marker in leptomeninges proximity cortex, accompanied memory decline in the middle-aged mice after systemic $P$. gingivalis infection. A, Time schedule of systemic P. gingivalis infection and memory behavior test. B, Systemic P. gingivalis infection for three weeks induced learning and memory deficits in middle-aged mice. C, Systemic P. gingivalis infection for three weeks did not change the body weight in middle-aged mice. Each column and bar represent the means \pm SEM $(n=6$, each). Asterisks indicate a statistically significant difference from the value for con group at the same time point. ( ${ }^{\star *} \mathrm{P}<0.001$, multiple $t$-test). $D$, The immunofluorescent CLMS images of brain slice stained with IL-1 $\beta$ (Green), Fibronectin (red) and DAPI (blue) after systemic P. gingivalis infection. ( $n=3$ mice, each). Scale bar $=25 \mu \mathrm{m}$. $E$, The quantitative analysis of IL-1 $\beta$ fluorescence density in fibronectin+ cells in (D). Asterisks indicate a statistically significant difference from the con group ( ${ }^{*} * \mathrm{P}<0.001$, t-test). $F$, The immunofluorescent CLMS images of brain slice stained with SYP (Green) and DAPI (blue) after systemic P. gingivalis infection. ( $\mathrm{n}=3$ mice, each). Scale bar $=25$ $\mu \mathrm{m} . \mathrm{G}$, The quantitative analysis of SYP fluorescence density in (F). Asterisks indicate a statistically significant difference from the con group ( $* \star * P<0.001$, t-test). $\mathrm{H}$, Pearson's correlation between the IL-1 $\beta$ in (D) and SYP in (F). 
A

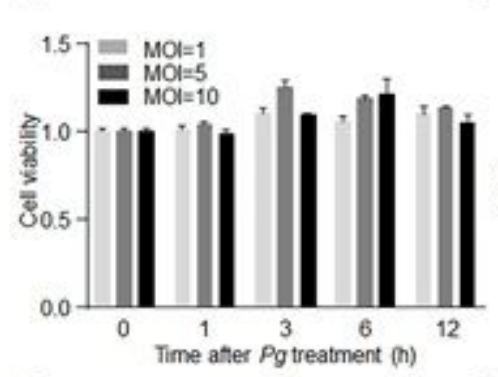

E

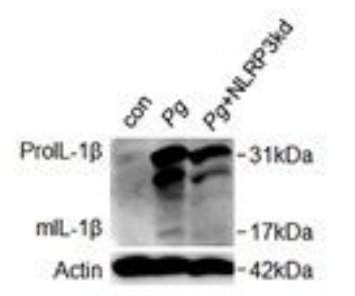

B

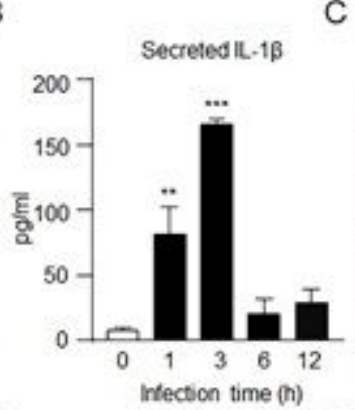

F $G$

G
K

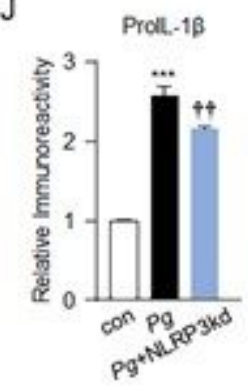

C
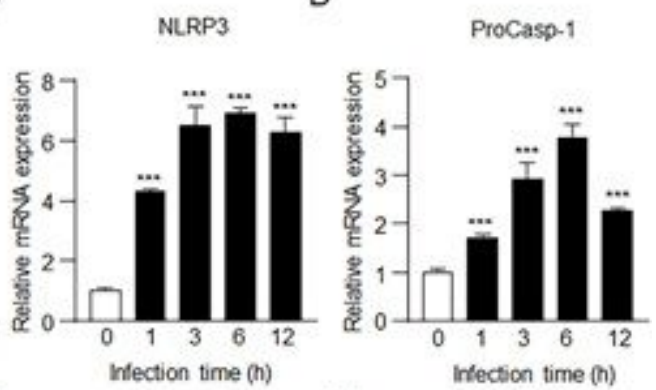

$\mathrm{H}$
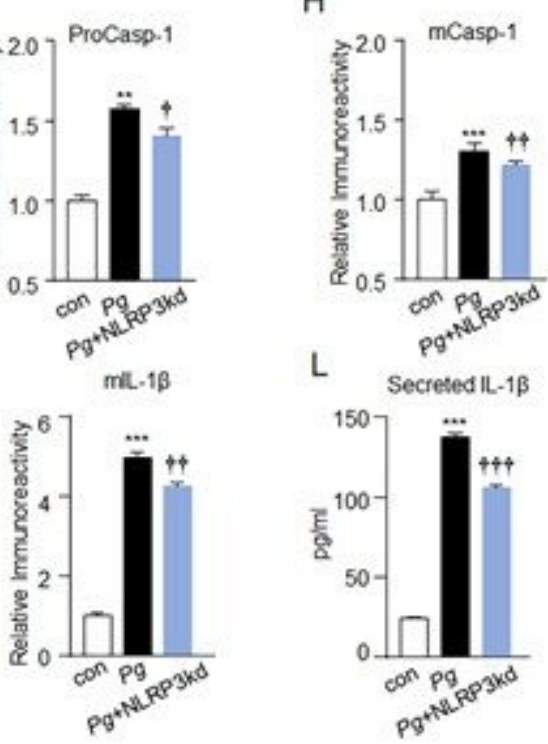

Figure 2

NLRP3 inflammasome involved in IL-1 $\beta$ secretion from primary leptomeningeal cells after $\mathrm{P}$. gingivalis infection A, The relative cell viability in P. gingivalis infected leptomeningeal cells with different MOls and time points. Each column and bar represent the mean \pm SEM $(n=3$, each). $B$, The secretion of IL-1 $\beta$ from leptomeningeal cells after infection with P. gingivalis for 1, 3, 6, and 12 hours. Each column and bar represent the mean \pm SEM $(n=3$, each). Asterisks indicate a statistically significant difference from the control group ( ${ }^{* * * P}<0.001, * * P<0.01$, t-test). C, D, The relative mRNA expression of NLRP3(C) and Caspase-1(D) in leptomeningeal cells after P. gingivalis infection with $\mathrm{MOI}=10$ for 1, 3, 6, and 12 hours. Each column and bar represent the mean $\pm \operatorname{SEM}(n=3$, each). Asterisks indicate a statistically significant difference from the control group ( $* \star * P<0.001$, t-test). E, Relative mRNA expression of NLRP3 in leptomeningeal cells with P. gingivalis infection for 3 hours in the presence or absence of NLRP3 siRNA. Each column and bar represent the mean $\pm \operatorname{SEM}(n=3$, each). Asterisks indicate a statistically significant difference between two groups ( ${ }^{* *} \mathrm{P}<0.001$, ${ }^{*} \mathrm{P}<0.01$, t-test). $\mathrm{F}$, The immunoblots show the pro- and mature-type of caspase-1 in leptomeningeal cells after infection with P. gingivalis for 3 hours in the presence or absence of NLRP3 siRNA. G, H, The quantitative analyses of the immunoblot in (F). Each column and bar represent the mean \pm SEM $(n=3$, each). Asterisks indicate a statistically significant difference from the control group $\left({ }^{*} * \mathrm{P}<0.001,{ }^{*} \mathrm{P}<0.01\right.$, $t$-test). Daggers indicate a statistically significant difference from the $P$. gingivalis infection group. ( $+\mathrm{P}<0.01,+\mathrm{P}<0.05$, $t$-test). I, The immunoblots show the pro- and mature-type of IL-1 $\beta$ in leptomeningeal cells after infection with P. gingivalis for 3 hours in the 
presence or absence of NLRP3 siRNA. J, K, The quantitative analyses of the immunoblots in (I). Each column and bar represent the mean \pm SEM $(n=3$, each). Asterisks indicate a statistically significant difference from the control group ( ${ }^{\star \star *} \mathrm{P}<0.001, \mathrm{t}$-test). Daggers indicate a statistically significant difference from the P. gingivalis infection group. ( $+T P<0.01$, $t$-test). $L, I L-1 \beta$ released from leptomeningeal cells after infection with P. gingivalis for 3 hours in the presence or absence of NLRP3 siRNA. Each column and bar represent the mean \pm SEM $(n=3$, each). Asterisks indicate a statistically significant difference from the control group ( ${ }^{* * *} \mathrm{P}<0.001, \mathrm{t}$-test). Daggers indicate a significant difference from the $\mathrm{P}$. gingivalis infection group. (†††P<0.001, t-test).

A

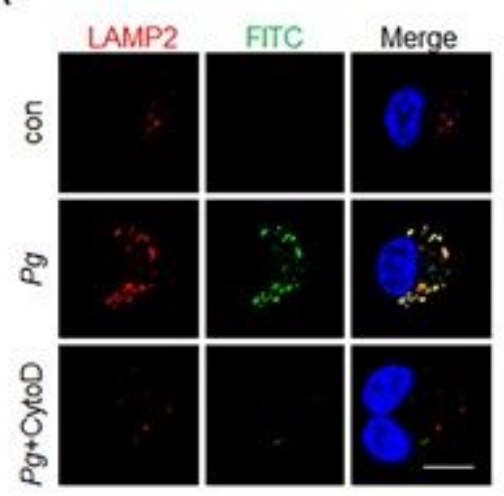

B

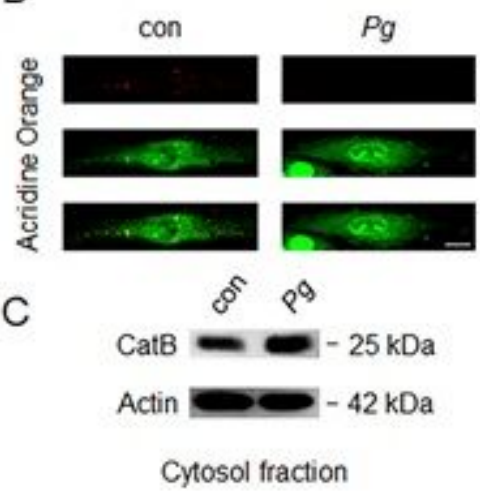

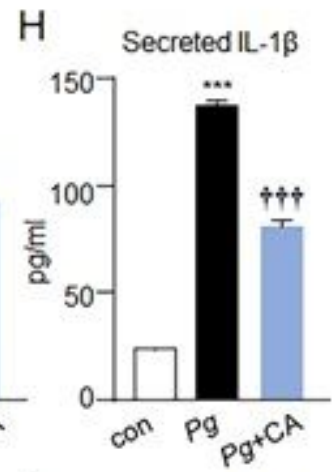

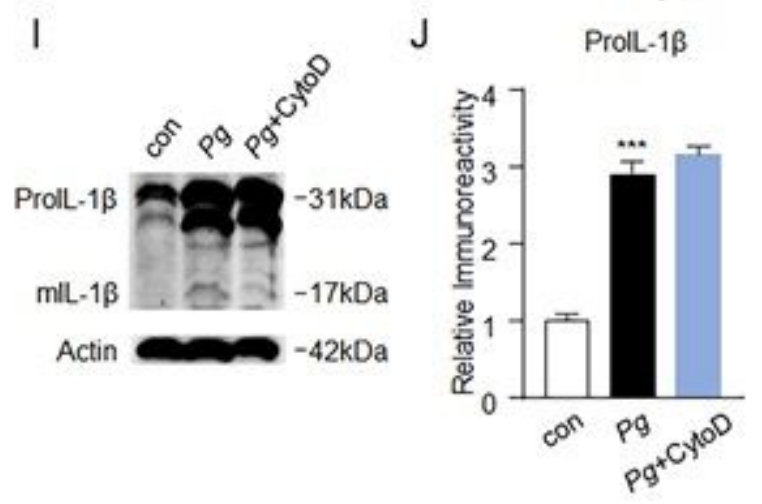

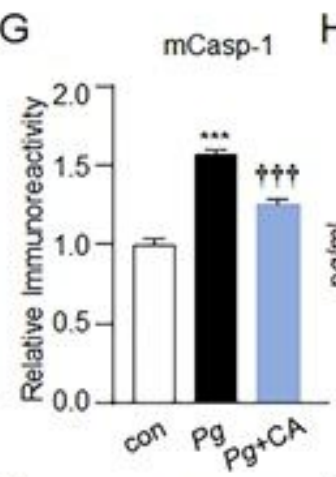

$\mathrm{K}$

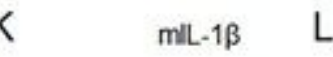

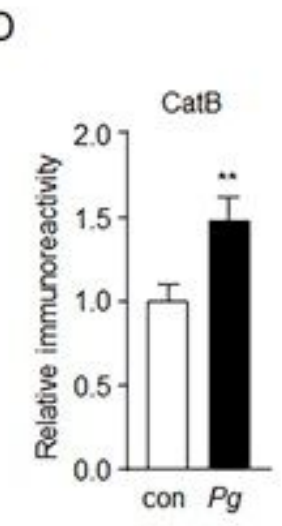

$\mathrm{H}$

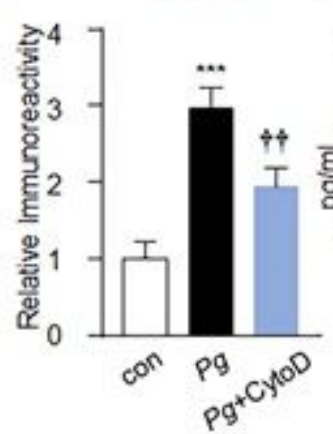

Secreted IL-1 $\beta$

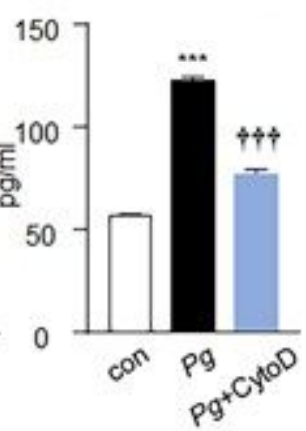

\section{Figure 3}

CatB involved in NLRP3 inflammasome activation in primary leptomeningeal cells after P. gingivalis infection A, CLMS images of P. gingivalis infected leptomeningeal cells for 1 hour. P. gingivalis was labeled with FITC (Green), endosome/lysosome was labeled with LAMP2 (Red). Scale bar $=20 \mu \mathrm{m}$. B, CLMS images of acridine orange in control and P. gingivalis infected leptomeningeal cells for 2 hours. 
Scale bar $=20 \mu \mathrm{m} . \mathrm{C}$, The immunoblots show the CatB in the cytosol of leptomeningeal cells after infection with P. gingivalis for 2 hours. D, The quantitative analyses of the immunoblot in (C). Each column and bar represent the mean \pm SEM $(n=3$, each). Asterisks indicate a statistically significant difference from the control group ( ${ }^{*} P<0.01$, t-test). $E$, The immunoblots show the pro- and mature-type of caspase- 1 in leptomeningeal cells after infection with P. gingivalis for 3 hours in the presence or absence of $10 \mu \mathrm{M}$ CA-074 Me. F, G, The quantitative analyses of the immunoblots in (E). Each column and bar represent the mean \pm SEM $(n=3$, each). Asterisks indicate a statistically significant difference from the control group ( ${ }^{\star * *} P<0.001, * * P<0.01, t$-test). Daggers indicate a statistically significant difference from the $P$. gingivalis infection group. ( $+\uparrow+P<0.001, t+P<0.01, t$-test). $H$, The IL- $1 \beta$ released from leptomeningeal cells after infection with P. gingivalis for 3 hours in the presence or absence of CA-074 Me. Each column and bar represent the mean \pm SEM $(n=3$, each). Asterisks indicate a statistically significant difference from the control group ( ${ }^{\star \star *} \mathrm{P}<0.001$, t-test). Daggers indicate a significant difference from the $\mathrm{P}$. gingivalis infection group. ( $+†+P<0.001$, t-test). I, The immunoblots show the pro- and mature-type of IL-1 $\beta$ in leptomeningeal cells after infection with $P$. gingivalis for 3 hours with or without $1 \mu M$ CytoD. J, $K$, The quantitative analyses of the immunoblot of pro- $(\mathrm{J})$ and mature-type $(\mathrm{K})$ of IL-1 $\beta$ in $(\mathrm{I})$. Each column and bar represent the mean \pm SEM $(n=3$, each). Asterisks indicate a statistically significant difference from the control group ( ${ }^{* *} P<0.001, t$-test). Daggers indicate a statistically significant difference from the $P$. gingivalis infection group. ( $++P<0.01$, $t$-test). $L$, The secretion of $I L-1 \beta$ from leptomeningeal cells after infection with P.gingivalis for 3 hours with or without Cyto D. Each column and bar represent the mean \pm SEM ( $n=3$, each). Asterisks indicate a statistically significant difference from the control group $(\star \star \star P<0.001, t$-test). Daggers indicate a statistically significant difference from the $P$. gingivalis infection group. (††+P<0.001, t-test). 


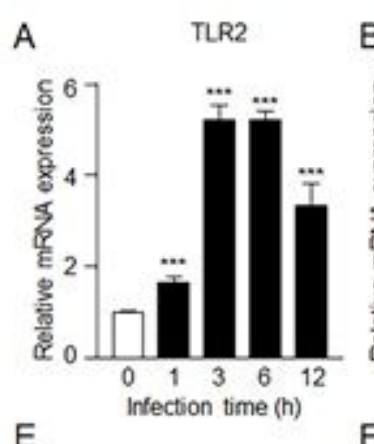

B CatB C

D

CatB

E

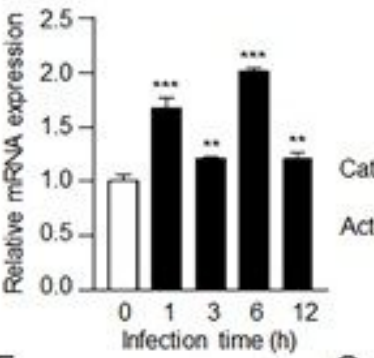

$\mathrm{F}$

IxBa/Actin

G
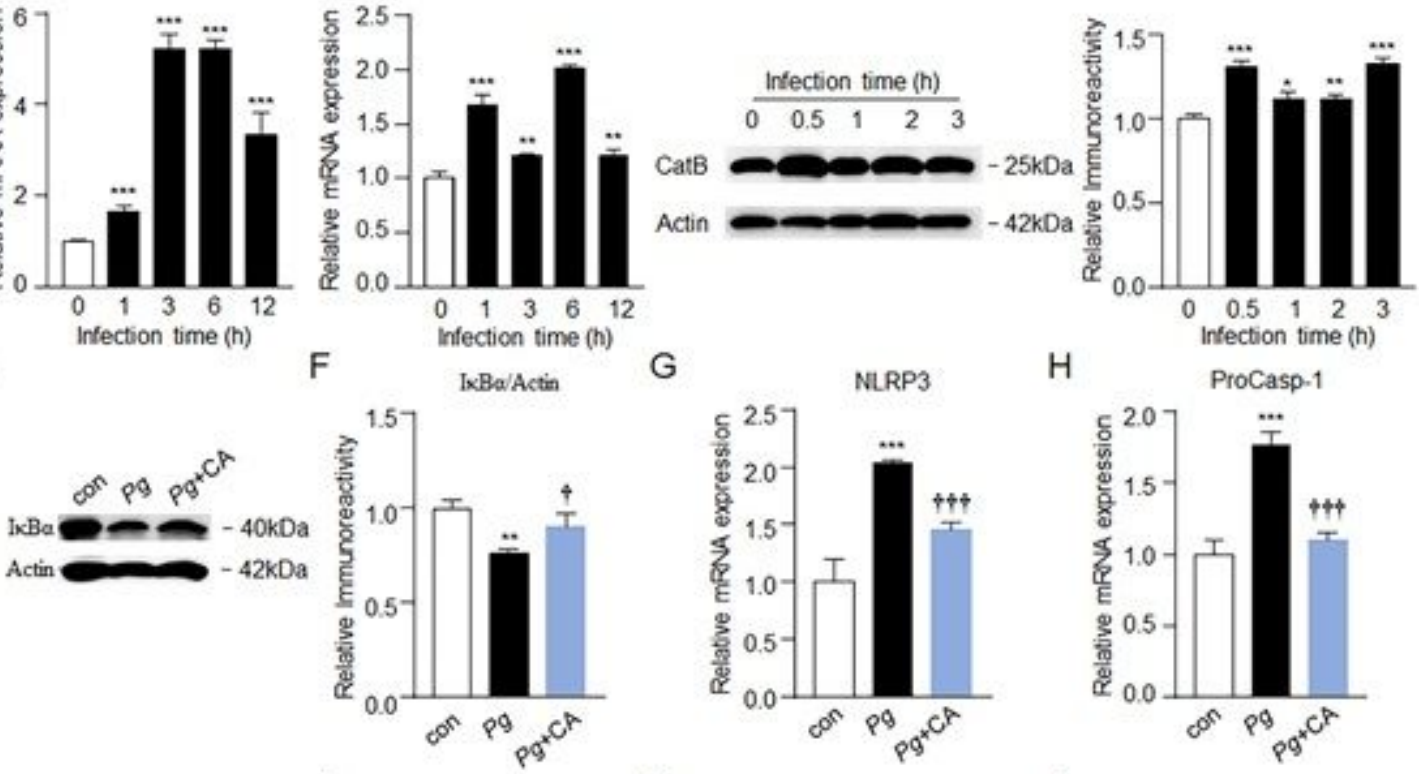

NLRP3

$\mathrm{H}$
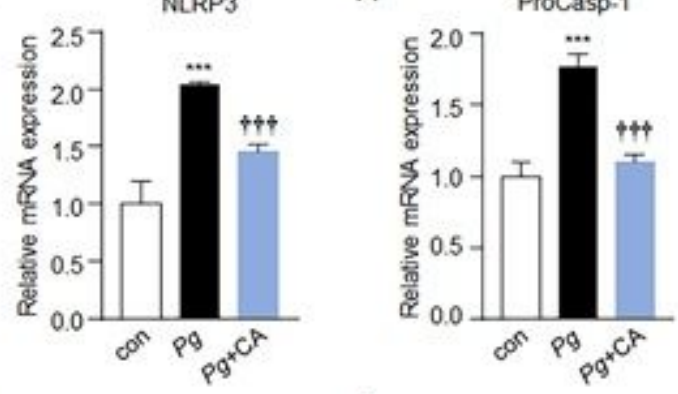

I
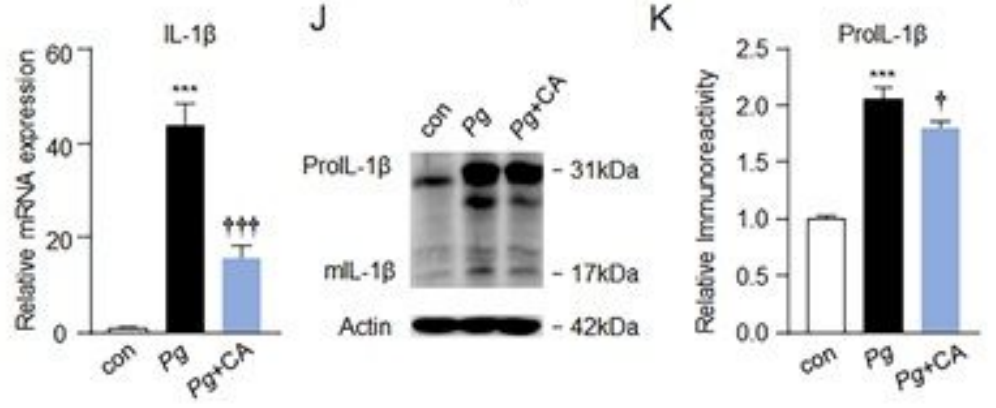

L

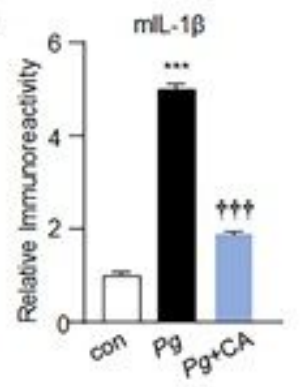

Figure 4

CatB involved in NF-KB activation for IL-1 $\beta$ production in leptomeningeal cells after $\mathrm{P}$. gingivalis infection $A, B$, The relative mRNA expression of TLR2(A) and $C a t B(B)$ in leptomeningeal cells after $P$. gingivalis infection with $\mathrm{MOI}=10$ for $1,3,6$, and 12 hours. Each column and bar represent the mean $\pm \operatorname{SEM}(n=3$, each). Asterisks indicate a statistically significant difference from the control group ( ${ }^{* \star *} P<0.001$, ${ }^{\star} * \mathrm{P}<0.01$, $\mathrm{t}$-test). $\mathrm{C}$, The immunoblots show the CatB in leptomeningeal cells after infection with $\mathrm{P}$. gingivalis for $0.5,1,2$, and 3 hours. $D$, The quantitative analyses of CatB in the immunoblot shown in (C). Each column and bar represent the mean \pm SEM $(n=3$, each). Asterisks indicate a statistically significant difference from the control group ( ${ }^{\star *} P<0.001,{ }^{*} P<<0.01,{ }^{*} P<0.05$, t-test). $E$, The immunoblots show the $\mathrm{IKBa}$ in leptomeningeal cells after infection with $\mathrm{P}$. gingivalis for 1 hour with or without pretreatment with $10 \mu \mathrm{M}$ CA-074 Me. F, The quantitative analyses of total IkBa in the immunoblot shown in (E). Each column and bar represent the mean $\pm \operatorname{SEM}(n=3$, each). Asterisks indicate a statistically significant difference from the control group ( ${ }^{* * P}<0.01$, t-test). A dagger indicates a significant difference from the $P$. gingivalis infection group. ( $+P<0.05$, t-test). $G, H, I$, Relative mRNA expression of NLRP3 (G), Caspase-1 $(H)$, and IL-1 $\beta(I)$ in leptomeningeal cells after $P$. gingivalis infection with or without CA-074 Me pretreatment. Each column and bar represent the mean \pm SEM $(n=3$, each). Asterisks indicate a statistically significant difference from the control group ( $* \star \star P<0.001, t$-test). Daggers indicate a statistically significant difference from the P. gingivalis infection group. (†††P<0.001, t-test). J, The 
immunoblots show the pro- and mature-type of IL-1 $\beta$ in leptomeningeal cells after infection with P. gingivalis for 3 hours in the presence or absence of CA-074 Me. K, L, The quantitative analyses of the immunoblots in $(J)$. Each column and bar represent the mean \pm SEM $(n=3$, each). Asterisks indicate a statistically significant difference from the control group ( ${ }^{\star * *} P<0.001$, t-test). Daggers indicate a statistically significant difference from the $P$. gingivalis infection group. ( $+\uparrow+P<0.001,+P<0.05$, t-test).

A

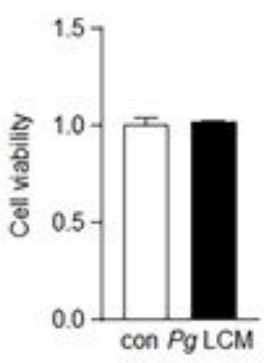

C

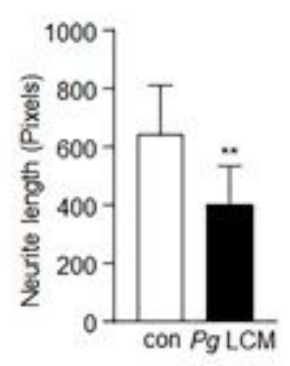

G

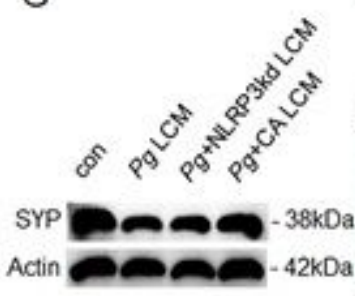

B

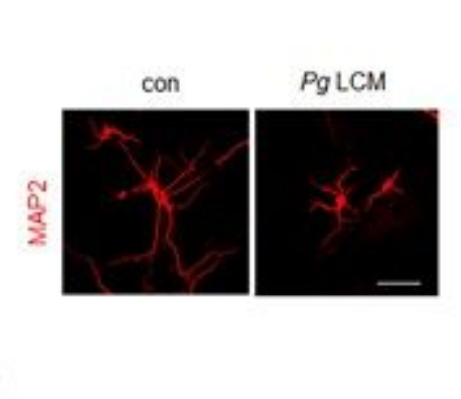

$\mathrm{E}$

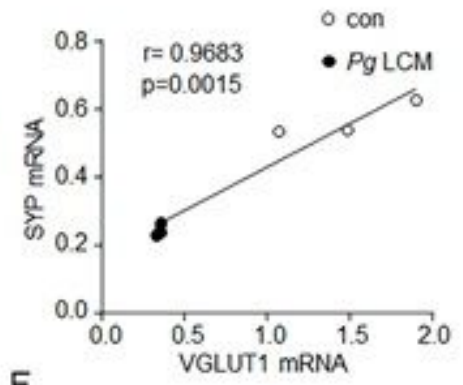

$\mathrm{F}$
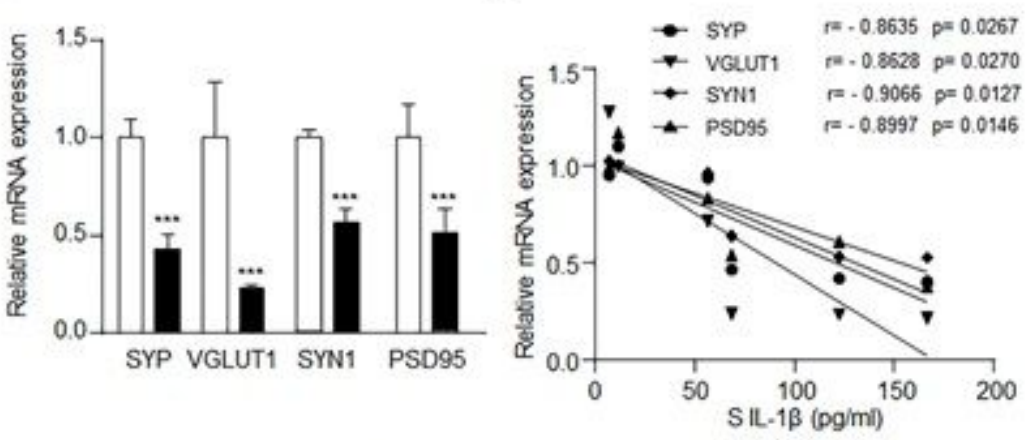

$\mathrm{H}$

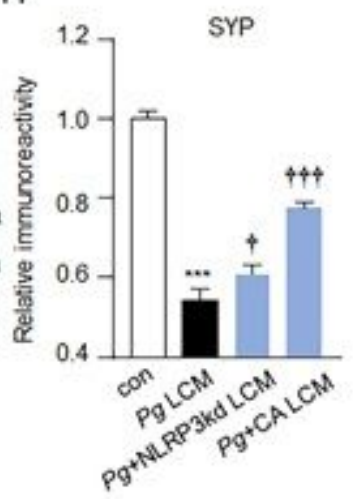

I

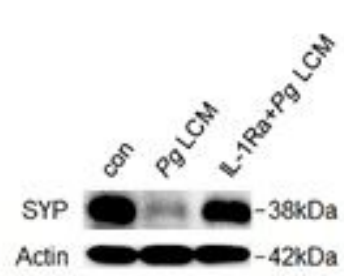

$\mathrm{J}$

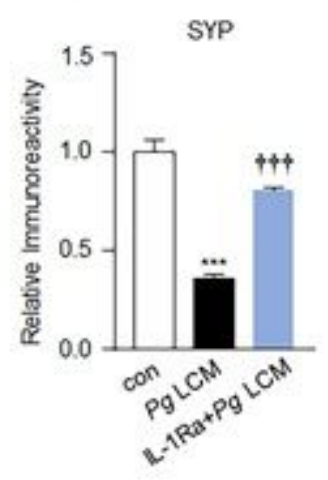

\section{Figure 5}

P. gingivalis infected leptomeningeal cells induced an IL-1 $\beta$-dependent synaptic distribution in neurons Condition medium from leptomeningeal cells infected by P. gingivalis for 3 hours with $\mathrm{MOI}=10$ (Pg LCM) in the presence or absence of NLRP3 siRNA (Pg+NLRP3kd LCM) or CA-074 Me (Pg+CA LCM) was collected and $30 \%$ of the neuron condition medium was replaced to culture primary neurons for 24 hours. $\mathrm{A}$, The relative cell viability in control and Pg LCM neurons. Each column and bar represent the mean \pm SEM ( $n=3$, each). B, CLMS images of primary neurons (MAP2, red) with or without Pg LCM treatment. C, The neurite length analyses of the neurons in $(B)$. Each column and bar represent the mean \pm SEM $(n=10$, each). Asterisks indicate a statistically significant difference from the control group ( ${ }^{\star} P<0.01, t$-test). $D$, The relative mRNA expression of SYP, VGLUT1, SYN1, and PSD95 in control and Pg LCM neurons. Each 
column and bar represent the mean \pm SEM $(n=3$, each). Asterisks indicate a statistically significant difference from the control group ( ${ }^{* *} \mathrm{P}<0.001$, t-test). E, Pearson's correlation between the VGLUT1 and SYP in (D). F, Pearson's correlation between the secreted IL-1 $\beta$ in Pg LCM and synaptic components in (D). $\mathrm{G}$, The immunoblots show SYP in control, Pg LCM, Pg+NLRP3kd LCM, and Pg+CA CLM incubated primary neurons. $\mathrm{H}$, Quantitative analyses of the immunoblots in (G). Each column and bar represent the mean \pm SEM $(n=3$, each). Asterisks indicate a statistically significant difference from the control group $(\star \star \star P<0.001, t$-test). Daggers indicate a statistically significant difference from the Pg LCM group. ( $+†+P<0.001, t P<0.05$, t-test). I, The immunoblots show SYP in primary neurons with or without $1 \mu \mathrm{g} / \mathrm{ml}$ IL-1Ra pretreatment followed by incubation with Pg LCM. J, Quantitative analyses of the immunoblots in (I). Each column and bar represent the mean \pm SEM ( $n=3$, each). Asterisks indicate a statistically significant difference from the control group ( $* \star * P<0.001$, t-test). Daggers indicate a statistically significant difference from the Pg LCM group. (†††P<0.001, t-test). 
A

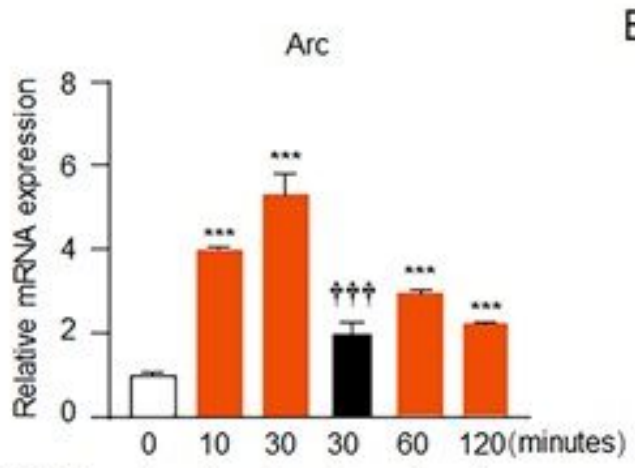

B

BDNF + + + + + +

C

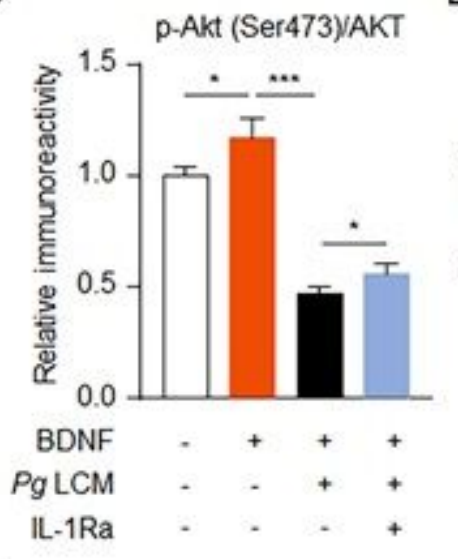

F

BDNF

LCM

IL-1Ra

p.CREB

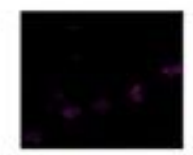

DAPI
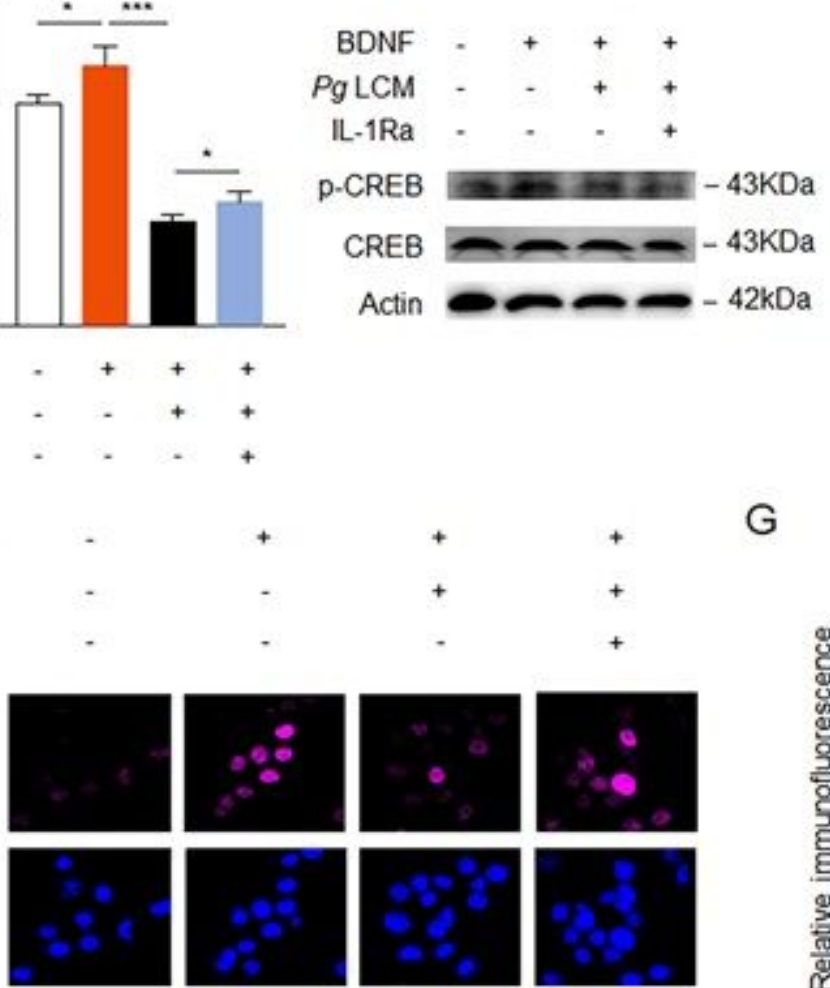

Actin

D

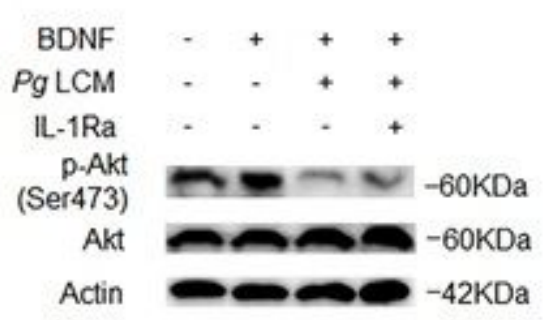

E

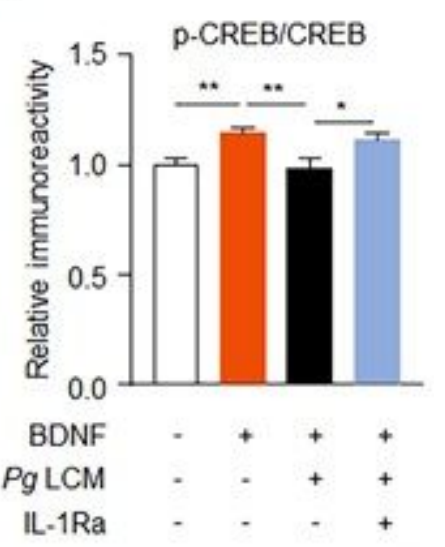

G

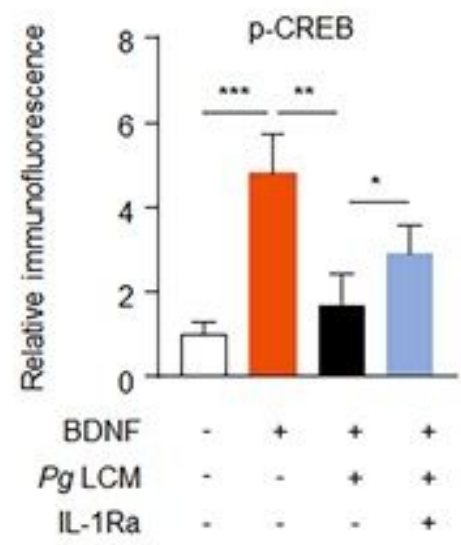

\section{Figure 6}

P. gingivalis infected leptomeningeal cells induced an IL-1 $\beta$-dependent suppression of BDNF signaling in neurons A, The relative mRNA expression of Arc in N2a cells after BDNF treatment for 10, 30, 60 and 120 minutes with or without $50 \% \mathrm{Pg}$ LCM incubation. Each column and bar represent the mean \pm SEM $(n=3$, each). Asterisks indicate a statistically significant difference from the control group ( ${ }^{\star} * \star P<0.001, t$-test). Daggers indicate a statistically significant difference from the Pg LCM incubated 30 minutes neurons. ( $+\uparrow+P<0.001$, t-test). B, The expression of $p$-Akt and total Akt protein after treatment with Pg LCM, 10 $\mathrm{ng} / \mathrm{ml} \mathrm{BDNF}$, and $1 \mu \mathrm{g} / \mathrm{ml}$ IL-1Ra. C, The quantitative analyses of $\mathrm{p}$-Akt/Akt in the immunoblot shown in 
(B). Each column and bar represent the mean $\pm \operatorname{SEM}(n=3$, each). Asterisks indicate a statistically significant difference ( ${ }^{\star *} * \mathrm{P}<0.001,{ }^{*} \mathrm{P}<0.05$, $\mathrm{t}$-test). $\mathrm{D}$, The expression of $\mathrm{p}$-CREB and total CREB protein after treatment with Pg LCM, BDNF, and IL-1Ra. E, The quantitative analyses of $p$-CREB/CREB in the immunoblot shown in (D). Each column and bar represent the mean $\pm \operatorname{SEM}(n=3$, each). Asterisks indicate a statistically significant difference $\left({ }^{* * P}<0.01,{ }^{*} P<0.05\right.$, t-test). $F, C L M S$ images of $p$-CREB after treatment with Pg LCM, BDNF and IL-1Ra. Scale bar $=10 \mu \mathrm{m}$. G, The quantitative analysis of relative p-CREB fluorescent in $(F)$. Each column and bar represent the mean $\pm \operatorname{SEM}(n=10$, each). Asterisks indicate a statistically significant difference between indicated groups ( ${ }^{\star * *} P<0.001,{ }^{*} * P<0.01,{ }^{*} P<0.1, t$-test).

A

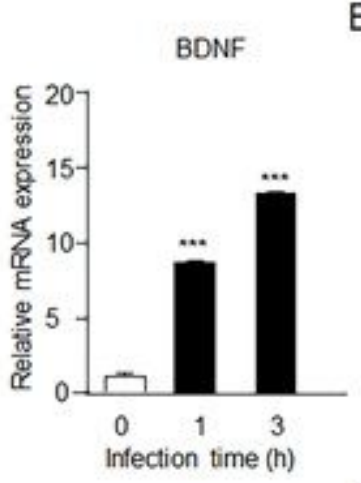

D

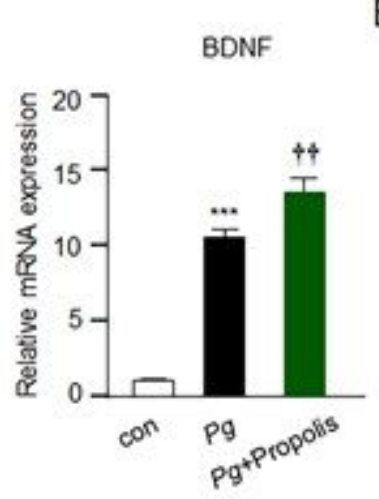

G

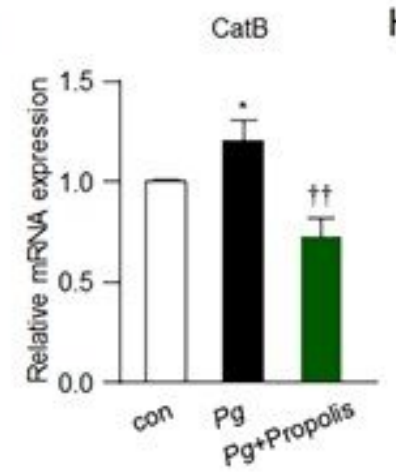

B

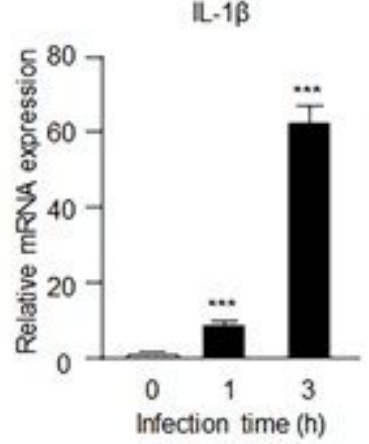

E

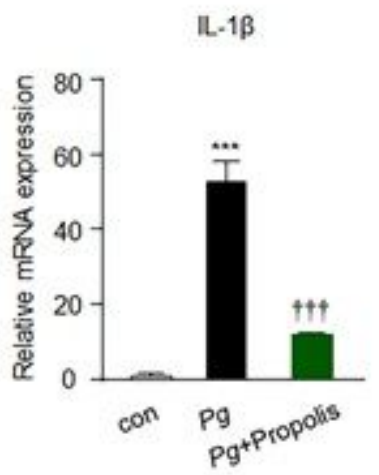

$\mathrm{H}$

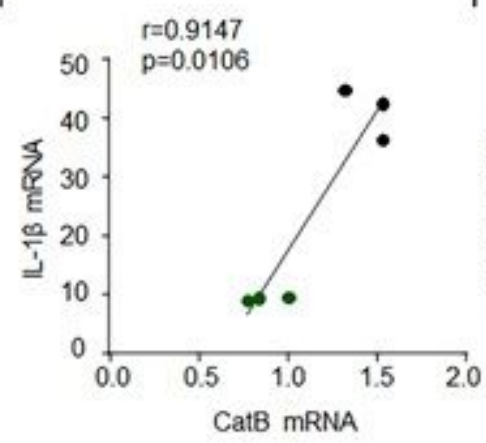

C

$\mathrm{F}$
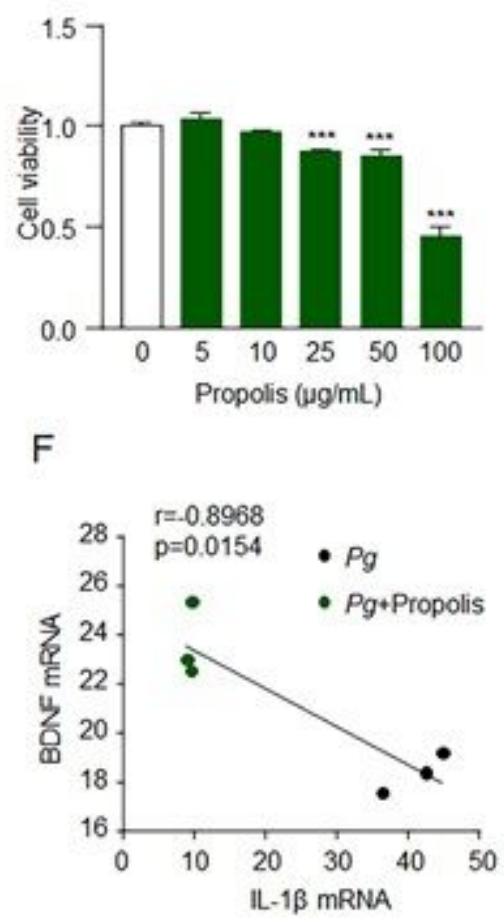

I

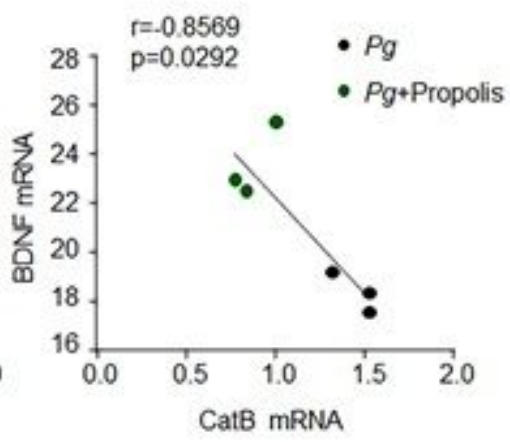

\section{Figure 7}

Propolis modulated the IL-1 $\beta$-related BDNF production in primary leptomeningeal cells after $\mathrm{P}$. gingivalis infection $A, B$, The relative $m R N A$ expression of $B D N F(A)$ and IL-1 $\beta(B)$ in leptomeningeal cells after $P$. gingivalis infection with $\mathrm{MOI}=10$ for 1 and 3hours. Each column and bar represent the mean \pm SEM $(n=3$, each). Asterisks indicate a statistically significant difference from the control group ( $* \star \star P<0.001, t$-test). C, Cell viability of leptomeningeal cells after propolis treatment with different concentrations. Each column 
and bar represent the mean \pm SEM $(n=3$, each). Asterisks indicate a statistically significant difference from the control group ( ${ }^{\star \star *} P<0.001$, t-test). $D, E$, The relative mRNA expression of BDNF (D) and IL-1 $\beta(E)$ in leptomeningeal cells after P. gingivalis infection with $\mathrm{MOI}=10$ for 3 hours with or without $10 \mu \mathrm{g} / \mathrm{ml}$ propolis 24 hours pretreatment. Each column and bar represent the mean \pm SEM ( $n=3$, each). Asterisks indicate a statistically significant difference from the control group ( ${ }^{\star * *} \mathrm{P}<0.001, \mathrm{t}$-test). Daggers indicate a statistically significant difference from the $P$. gingivalis infection group. ( $+\uparrow P<0.001,+\uparrow P<0.01$, t-test). F, Pearson's correlation between the IL-1 $\beta$ and BDNF in (E). G, The relative mRNA expression of CatB in leptomeningeal cells after $\mathrm{P}$. gingivalis infection with $\mathrm{MOI}=10$ for 3 hours with or without propolis 24 hours pretreatment. Each column and bar represent the mean $\pm \operatorname{SEM}(n=3$, each). Asterisks indicate a statistically significant difference from the control group ( ${ }^{*} P<0.05$, t-test). Daggers indicate a statistically significant difference from the P. gingivalis infection group. (†tP<0.01, t-test). $\mathrm{H}, \mathrm{l}$, Pearson's correlation between the CatB in (G) and IL-1 $\beta$ in (E)/BDNF in (D).

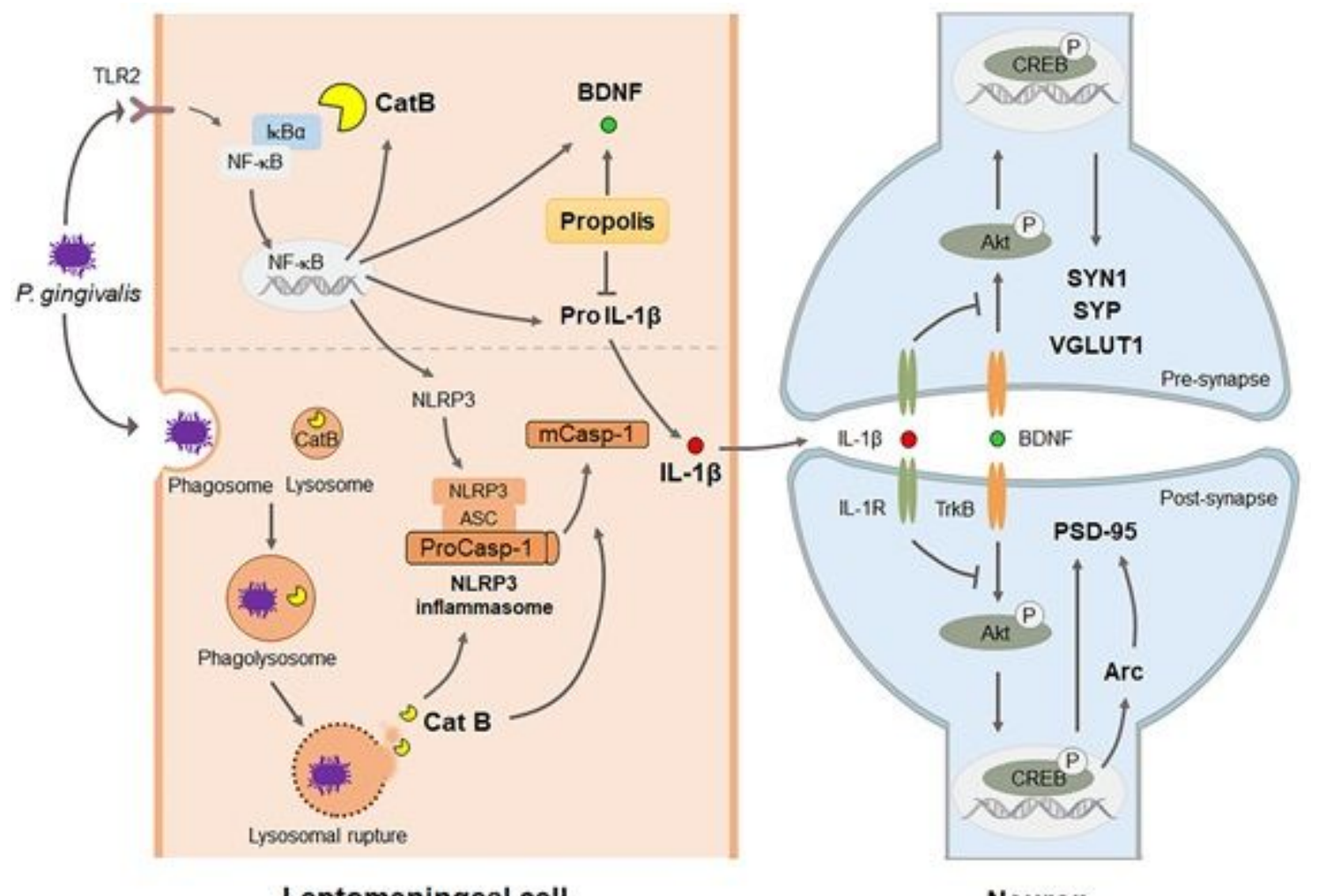

Leptomeningeal cell

Neuron

\section{Figure 8}

Leptomeningeal cells might induce synaptic failure via the CatB-mediated IL-1 $\beta$ production after $P$. gingivalis infection. P. gingivalis activated NF-KB signaling to produced pro IL-1区, NLRP3, pro-caspase-1 and CatB. CatB degraded the IкBa to further activate NF-кB signaling. At the same time, P. gingivalis was phagocyted by leptomeningeal cells and invaded into the phagolysosome inducing lysosomal rupture resulted in CatB leakage into the cytosol. The CatB in cytosol was able to activate NLRP3 inflammasome inducing pro-caspase- 1 autocatalysis to active caspase- 1 and the activated caspase- 1 enzyme the pro-IL$1 \beta$ to its mature form and secreted from leptomeningeal cells. The secreted IL- $1 \beta$ interfering the BDNF/Akt/CREB signaling resulted the synaptic molecules, including SYP, SYN1, VGLUT1, PSD-95, and 
the Arc gene got influenced. In the meantime, propolis was able to modulate the expression of BDNF and pro IL-1 $\beta$ which may benefit the neuron protection in P. gingivalis infection.

\section{Supplementary Files}

This is a list of supplementary files associated with this preprint. Click to download.

- Additionalfile1.docx

- Additionalfile2.docx 